\title{
Multifaceted C-X-C Chemokine Receptor 4 (CXCR4) Inhibition Interferes with Anti-Vascular Endothelial Growth Factor Therapy-Induced Glioma Dissemination
}

Jean-Pierre Gagner, ${ }^{* \dagger}$ Yasmeen Sarfraz, ${ }^{* \dagger}$ Valerio Ortenzi, ${ }^{* \dagger}$ Fawaz M. Alotaibi, ${ }^{\dagger \dagger}$ Luis A. Chiriboga, ${ }^{\dagger}$ Awab T. Tayyib, ${ }^{* \dagger}$ Garry J. Douglas, ${ }^{\ddagger}$ Eric Chevalier, ${ }^{\ddagger}$ Barbara Romagnoli, ${ }^{\ddagger}$ Gérald Tuffin, ${ }^{\ddagger}$ Michel Schmitt, ${ }^{\ddagger}$ Guillaume Lemercier, ${ }^{\ddagger}$ Klaus Dembowsky, ${ }^{\ddagger}$ and David Zagzag ${ }^{\star \dagger \S \uparrow \|}$

From the Microvascular and Molecular Neuro-Oncology Laboratory, ${ }^{*}$ the Division of Neuropathology, ${ }^{\S}$ Department of Pathology, ${ }^{\dagger}$ and the Department of Neurosurgery, "New York University Langone Medical Center, New York, New York; Polyphor Ltd., ${ }^{\ddagger}$ Allschwil, Switzerland; and the New York University Langone Laura and Isaac Perlmutter Cancer Center, "New York, New York

Accepted for publication April 5, 2017.

Address correspondence to David Zagzag, M.D., Ph.D., Department of Pathology, NYU Langone Medical Center, 550 First Ave, New York, NY 10016. E-mail: david. zagzag@nyumc.org.

\begin{abstract}
Resistance to antiangiogenic therapy in glioblastoma (GBM) patients may involve hypoxia-induced expression of C-X-C motif chemokine receptor 4 (CXCR4) on invading tumor cells, macrophage/microglial cells (MGCS), and glioma stem cells (GSCS). We determined whether antagonizing CXCR4 with POL5551 disrupts anti-vascular endothelial growth factor (VEGF) therapy-induced glioma growth and dissemination. Mice bearing orthotopic CT-2A or GL261 gliomas received P0L5551 and/or anti-VEGF antibody B20-4.1.1. Brain tissue was analyzed for tumor volume, invasiveness, hypoxia, vascular density, proliferation, apoptosis, GSCs, and MGCs. Glioma cells were evaluated for CXCR4 expression and polymorphism and POL5551's effects on CXCR4 ligand binding, cell viability, and migration. No CXCR4 mutations were identified. POL5551 inhibited CXCR4 binding to its ligand, stromal cell-derived factor- $1 \alpha$, and reduced hypoxia- and stromal cell-derived factor- $1 \alpha$-mediated migration dose - dependently but minimally affected cell viability. In vivo, B20-4.1.1 increased hypoxic foci and invasiveness, as seen in GBM patients receiving anti-VEGF therapy. Combination of POL5551 and B204.1.1 reduced both glioma invasiveness by $16 \%$ to $39 \%$ and vascular density compared to B20-4.1.1 alone in both glioma models. Reduced populations of GSCs and MGCs were also seen in CT-2A tumors. POL5551 concentrations, evaluated by mass spectrometry, were higher in tumors than in neighboring brain tissues, likely accounting for the results. Inhibition of CXCR4-regulated tumoral, stem cell, and immune mechanisms by adjunctive CXCR4 antagonists may help overcome antiangiogenic therapy resistance, benefiting GBM patients. (Am J Pathol 2017, 187: 2080-2094; http://dx.doi.org/10.1016/ j.ajpath.2017.04.020)
\end{abstract}

Supported by NIH/National Cancer Institute grants R21NS074055 (D.Z.) and P30CA016087 and NIH/Office of Research Infrastructure Programs grants S10OD01058 and S10OD018338 (for the Experimental Pathology Immunohistochemistry Core Laboratory of the Laura and Isaac Perlmutter Cancer Center; L.A.C.).

J.-P.G. and Y.S. contributed equally to this work.

Disclosures: G.J.D., E.C., B.R., G.T., M.S., G.L., and K.D. are employed by, and own shares in, Polyphor Ltd. Polyphor Ltd provided the drug POL5551 for investigational purposes but did not fund the studies. Genentech, Inc., provided the antibody B20-4.1.1 for investigational purpose.
Presented in part at the $19^{\text {th }}$ Annual Scientific Meeting of the Society for Neuro-Oncology, November 13-16, 2014, Miami, FL; and the American Association for Cancer Research Special Conference Advances in Brain Cancer Research, May 27-30, 2015, Washington, DC.

Current address of Y.S., Department of Radiation Oncology, Weill Cornell Medical College, New York, NY; of V.O., Division of Pathology, University Hospital of Pisa and University Hospital of Cagliari, Pisa, Italy; of F.M.A., Division of Neurosurgery, The Ottawa Hospital, University of Ottawa, Ontario, ON, Canada. 
Despite the promising initial radiographic and progressionfree survival responses of patients with glioblastoma (GBM) to antiangiogenic therapy, most patients who receive the anti-vascular endothelial growth factor (VEGF) antibody bevacizumab (BEV; Avastin; Genentech, Inc., South San Francisco, CA) fail to demonstrate an overall survival benefit and develop disseminated relapse ${ }^{1-3}$ associated with vascular remodeling and metabolic adaptation to tumor hypoxia. ${ }^{4-6}$ Unlike cancers that develop resistance to therapy from genetic mutation of drug targets, gliomas either possess intrinsic resistance or acquire secondary resistance to BEV by bypassing antiangiogenic therapy (while VEGF signaling remains inhibited) through several mechanisms, ${ }^{1,2}$ leading to further tumor growth and dissemination. These mechanisms include upregulation of alternate proangiogenic factors by tumor or stromal cells [eg, stromal cell-derived factor (SDF)-1 $\alpha$ (CXCL12) and C-X-C motif chemokine receptor 4 (CXCR4)], accumulation of tumor-initiating glioma stem cells (GSCs), ${ }^{8}$ and infiltration of gliomaassociated myeloid cells that promote tumor growth, migration, and immunosuppression. ${ }^{8-10}$ Combining angiogenesis inhibitors with drugs targeting these parallel mechanisms of resistance may provide more durable antiangiogenic efficacy and improve patient outcome. ${ }^{1,2,11,12}$ Recent clinical trials with BEV in combination with other therapies have renewed interest in targeting angiogenesis in GBMs. For the first time, an overall survival benefit was observed with BEV combined with the alkylating agent lomustine in patients with recurrent $\mathrm{GBM}^{13,14}$ or with temozolomide and radiotherapy in patients with proneural GBM in the AVAglio trial. ${ }^{15}$ Improved survival was also demonstrated in a subset of newly diagnosed GBM patients who showed increased tumor blood perfusion after VEGF receptor kinase inhibitor cediranib and chemoradiation. ${ }^{16}$

The SDF- $1 \alpha$ receptor CXCR4, which is overexpressed in numerous human cancers, ${ }^{17}$ including glioma, ${ }^{18,19}$ has been shown to promote tumor growth, invasion, angiogenesis, metastasis, relapse, and therapeutic resistance. ${ }^{20,21}$ In GBMs, BEV may promote invasion by hypoxic glioma cells into the brain, at least in part, through mechanisms that involve hypoxia-induced expression of CXCR4 on invading tumor cells and migration of these cells toward central nervous system neurons and blood vessels, which are known to express SDF- $1 \alpha .^{22,23}$ This effect may be mediated by enhanced phosphorylation of proline-rich tyrosine kinase $2,{ }^{24}$ a signaling effector of CXCR4-regulated glioma chemotaxis. ${ }^{18}$ Similar mechanisms have been implicated in the migration of CXCR4-expressing GSCs ${ }^{8,25-27}$ and the tropism of glioma-associated CXCR4-expressing myeloid cells in regions with heightened glioma invasion. ${ }^{8-10}$ Inhibition of SDF-1 $\alpha /$ CXCR4 signaling has been found to reduce brain tumor growth and/or recurrence, ${ }^{28,29}$ the viability and number of GSCs, ${ }^{28,30}$ and the recruitment of glioma-associated macrophage/microglial cells (MGCs). ${ }^{9,10}$

We sought to disrupt the growth and dissemination of GBM by targeting CXCR4-regulated mechanisms using a novel, more potent antagonist. POL5551 ${ }^{31}$ belongs to a class of novel and selective CXCR4 antagonists developed by Polyphor, Ltd (Allschwil, Switzerland) using the proprietary protein epitope mimetic (PEM) technology ${ }^{32}$ and has shown to be markedly more potent (approximately 200-fold) than the bicyclam AMD3100 (plerixafor; Genzyme Corp., Cambridge, MA) in functional assays. ${ }^{31}$ Using two orthotopic immunocompetent murine glioma models previously shown to emulate the human GBM phenotype (eg, finger-like protrusions and single-cell infiltration), CT-2A $\mathrm{A}^{33}$ and GL261, ${ }^{23,34}$ we sought to determine whether POL5551 could disrupt glioma tumor growth and/or invasion triggered by antiangiogenic therapy with anti-murine VEGF neutralizing monoclonal antibody B20-4.1.1 (Genentech, Inc.). ${ }^{35}$ To evaluate the mechanisms of action of POL5551 in GBMs, its effects on tumor hypoxia, vascular density, proliferation, and apoptosis were examined. Because GBMs have been reported to contain GSCs that express CXCR $4^{26,27,30}$ and are infiltrated by tumor-associated myeloid cells that express CXCR $4,{ }^{9,36}$ we also assessed the tumor content of GSCs and glioma-associated MGCs. Our studies are supported by analyses of glioma CXCR4 gene polymorphism and POL5551 pharmacokinetics as well as in vitro studies of POL5551 binding to CXCR4 and its effects on glioma cell viability and migration.

In the present study, using mouse glioma models in which administration of anti-VEGF antibody B20-4.1.1 recapitulated the invasive phenotype seen in human GBM during BEV therapy, we demonstrated, for the first time, that when combined with B20-4.1.1, the CXCR4 antagonist POL5551 reduced glioma invasion and the number of tumorassociated MGCs, known to promote glioma growth and dissemination. In addition, no CXCR4 mutations were identified in glioma cells that could alter their function or response to treatment.

\section{Materials and Methods}

\section{Cell Culture and Pharmaceuticals}

Murine CT-2A (a gift from Dr. Thomas Seyfried, Boston College, MA) and GL261 (purchased from the Division of Cancer Treatment and Diagnosis, National Cancer Institute, Frederick, MD) glioma cells were cultured to $80 \%$ confluence in Dulbecco's modified Eagle's medium (DMEM; Cellgro, Manassas, VA) supplemented with $10 \%$ heatinactivated fetal bovine serum (FBS; Gemini BioProducts, West Sacramento, CA), $2 \mathrm{mmol} / \mathrm{L}$ glutamine, and $1 \%$ penicillin/streptomycin (CT-2A) or $0.25 \%$ gentamicin (GL261) at $37^{\circ} \mathrm{C}$ in a humidified $5 \% \mathrm{CO}_{2}$ incubator. These cell lines were authenticated using mouse short tandem repeat DNA profiling and tested by PCR to be free of Mycoplasma contamination (DDC Medical, Fairfield, OH). After trypsinization, cells were resuspended in RPMI 1640 medium (Cellgro) without serum for animal experimentations or DMEM with 1\% FBS for in vitro assays. POL5551 
acetate was supplied by Polyphor, Ltd, and B20-4.1.1 antibody by Genentech, Inc.; both drugs were dissolved in phosphate-buffered saline (PBS) before use. Recombinant mouse SDF- $1 \alpha$ and AMD3100 were purchased from R\&D Systems Inc. (Minneapolis, MN) and Sigma-Aldrich (St. Louis, MO), respectively.

\section{Animal Experiments}

In accordance with the NIH's Guide for the Care and Use of Laboratory Animals ${ }^{37}$ and a protocol approved by the New York University Institutional Animal Care and Use Committee, glioma cells were implanted into the brains of mice, as previously described. ${ }^{23}$ Briefly, 10 - to 12 -week-old female C57BL/6 mice (20 g) (Taconic Biosciences, Germantown, NY) were housed under pathogen-free conditions. After general anesthesia with $90 \mathrm{mg} / \mathrm{kg}$ ketamine i.p. and $10 \mathrm{mg} / \mathrm{kg}$ xylazine chloride hydrate i.p., mice were secured in a stereotactic frame, and a burr hole was drilled into the skull 0.1 $\mathrm{mm}$ posterior to the bregma and $2.3 \mathrm{~mm}$ lateral to the midline. CT-2A or GL261 cells $\left(1 \times 10^{5}\right)$ in $2 \mu \mathrm{L}$ of RPMI 1640 medium were injected to a depth of $2.35 \mathrm{~mm}$ from the cortical surface into the right caudate/putamen. On day 14 after implantation, mice were randomized into four treatment groups ( $n=9$ to 10 per group): i) control, ii) POL5551 (5 $\mathrm{mg} / \mathrm{kg}$ s.c. twice daily), iii) B20-4.1.1 antibody ( $5 \mathrm{mg} / \mathrm{kg}$ i.p. twice weekly), and iv) combined POL5551 and B20-4.1.1. Mice were examined daily, and only one moribund mouse was excluded. On day 26, $60 \mathrm{mg} / \mathrm{kg}$ pimonidazole (Hypoxyprobe, Burlington, MA) was injected i.p. 1 hour before sacrifice to detect foci of tumor hypoxia. Mice were anesthetized and perfused intracardially with PBS, followed by 4\% paraformaldehyde; the brains were harvested, placed in cold $4 \%$ paraformaldehyde overnight, sliced into 2 -mm coronal sections, and embedded in paraffin. Tissue sections (4 $\mu \mathrm{m}$ thick) were stained with hematoxylin and eosin or immunostained, digitized, and analyzed by image processing or visual scoring, as described below.

\section{Immunohistochemistry}

Immunohistochemistry was performed on a Discovery XT platform (Ventana Medical Systems, Tucson, AZ) using Ventana's reagents and detection kits, unless otherwise noted. Sections were immunostained to measure hypoxia (pimonidazole), vascular density (CD105/endoglin), cellular proliferation [phosphohistone $\mathrm{H} 3 \quad(\mathrm{pHH} 3)],{ }^{38}$ apoptosis (cleaved caspase 3), macrophage/microglial cells [ionized calcium binding adaptor molecule 1 (Iba1)], $, 39,40$ and glioma stem cells (nestin) ${ }^{41,42}$ using primary antibodies diluted in Dulbecco's PBS: mouse monoclonal anti-pimonidazole (1:50 dilution, HP2-100; Hypoxyprobe), goat anti-mouse CD105 (1:200 dilution, AF1320; R\&D Systems, Minneapolis, MN), rabbit anti-mouse pHH3 (1:400 dilution, 369A-15; Cell Marque, Rocklin, CA), rabbit anti-mouse cleaved caspase 3 (1:100 dilution, number 9661; Cell
Signaling Technology, Danvers, MA), rabbit anti-mouse Iba1 (1:500 dilution, number 019-19741; Wako Chemicals USA, Richmond, VA), and rabbit anti-mouse nestin tail (1:2000 dilution, PRB-336C; BioLegend, San Diego, CA) antibodies. After deparaffinization and rehydration, antigen retrieval was performed for $\mathrm{pHH} 3$ (10 minutes), caspase 3 (10 minutes), pimonidazole (20 minutes), and CD105 (20 minutes) by $1200-\mathrm{W}$ microwave heating in $10 \mathrm{mmol} / \mathrm{L}$ sodium citrate, $\mathrm{pH}$ 6.0. Iba1 and nestin were processed without epitope retrieval. Endogenous peroxidase activity was blocked with 3\% hydrogen peroxide for 4 minutes for all samples. Primary antibodies against pimonidazole, CD105, pHH3, and caspase 3 were incubated overnight, and those against Ibal and nestin were incubated for 3 and 6 hours, respectively, at room temperature. Pimonidazole was detected with rabbit anti-fluorescein isothiocyanate-horseradish peroxidase antibody (1:150) and incubated for 30 minutes, CD105 with biotinylated horse anti-goat antibody (1:100) for 30 minutes, and $\mathrm{pHH} 3$ and caspase 3 with biotinylated goat anti-rabbit antibody (1:200) for 30 minutes (all from Vector Laboratories, Burlingame, CA), followed by application of streptavidin-horseradish peroxidase conjugate. Ibal and nestin were detected with rabbit anti-horseradish peroxidase antibody (Ventana Medical Systems) and incubated for 8 minutes. Immune complexes were visualized with 3,3'-diaminobenzidene and enhanced with copper sulfate. Slides were washed in distilled water, counterstained with hematoxylin, dehydrated, and mounted with Permount mounting medium. Appropriate positive and negative tissue controls were included with the study sections.

\section{Image Analysis}

All histological sections were digitized (resolution, $0.5 \mu \mathrm{m} / \mathrm{pixel}$ ) using the SCN400 Slide Scanner (Leica Microsystems, Buffalo Grove, IL) and analyzed in a doubleblinded manner by at least two independent observers (Y.S., V.O., F.M.A, and/or A.T.T.). Using ImageJ software version 1.47 (NIH, Bethesda, MD; http://imagej.nih.gov/ij), tumor volume was calculated from tissue sections near the site of tumor cell implantation using the following equation: Tumor Volume $=\left(\right.$ Length $\left.\times \mathrm{Width}^{2}\right) / 2$, for a prolate ellipsoid, where length and width are the length and width of the tumor, respectively. As the irregularity of the tumor border increases with its invasiveness, the ratio between the perimeter and surface area increases as well. Tumor invasiveness (INV), a unitless value, was calculated by comparing the ratio of the perimeter $(\mathrm{P})$ and surface area (S) of tumors using the following equation: $\mathrm{INV}=\mathrm{P} / \sqrt{4 \pi \mathrm{S}} .^{43} \mathrm{~A}$ noninvasive, spherical tumor would have INV $=1.0$, whereas a tumor with a highly irregular border made of finger projections and islands of invasive cells would have a high INV value. ${ }^{43}$ Using ImageJ, the entire tumor perimeter and surface area, including all clusters of tumor cells $\left(>20 \mu \mathrm{m}^{2}\right)$, were delineated, measured, and summed for each tumor. 
To determine the mitotic rate, $\mathrm{pHH} 3$-stained sections were analyzed for positive staining and morphological features of mitotic figures ${ }^{38}$ after scale setting (100 pixels $\left./ \mu \mathrm{m}\right)$, color channel split, and threshold optimization using ImageJ. To determine tumor hypoxia, vascular density, and apoptosis, sections immunostained for pimonidazole, CD105, or caspase 3 were enumerated for the number and area of hypoxic foci, number of positive vessels, and number of apoptotic cells, respectively. ${ }^{22}$ Finally, to quantify MGCs and GSCs, sections immunostained for Iba1 ${ }^{39,40}$ and nestin ${ }^{41,42}$ were enumerated by scoring the percentage of positively stained cells in tumors on a 1 to 4 scale ( 1 if $<1 \%, 2$ if $1 \%$ to $10 \%, 3$ if $11 \%$ to $50 \%$, and 4 if $51 \%$ to $100 \%)$. The Ibal staining pattern of tumors was also described qualitatively as strongly central, central, central and peripheral, peripheral, or strongly peripheral. Discrepancies in scoring between observers were resolved by reaching consensus.

\section{Pharmacokinetics of P0L5551}

Mice bearing CT-2A or GL261 tumors were randomized into four treatment groups ( $n=4$ to 6 per group) in separate experiments on day 14 after implantation and administered B20-4.1.1 (5 mg/kg i.p. twice weekly) and/or POL5551 [either as a single dose $(5 \mathrm{mg} / \mathrm{kg}$ s.c. at $0.5,2,6$, and 24 hours before collection) or repeatedly $(5 \mathrm{mg} / \mathrm{kg}$ s.c. twice daily for 12 days, with the last doses at 0.5 and 2 hours before collection on day 26 after implantation)]. Blood samples were collected in lithium heparin Microtainer tubes with plasma separators (BD, Franklin Lakes, NJ) and spun at $800 \times g$ at $4^{\circ} \mathrm{C}$, and the plasma was stored at $-80^{\circ} \mathrm{C}$. Brains were harvested and dissected into tumor tissue, brain adjacent to tumor, and contralateral brain tissue. Each piece was weighed, snap frozen in liquid nitrogen, and stored at $-80^{\circ} \mathrm{C}$. Samples $(50 \mu \mathrm{L})$ were spiked with a PEM internal standard (P0006582) and extracted with acetonitrile plus $2 \%$ formic acid, and the supernatant was evaporated and reconstituted in water/acetonitrile $(95: 5, \mathrm{v} / \mathrm{v})$ plus $0.2 \%$ formic acid. The tissue concentration of POL5551 was determined by reverse phase liquid chromatography (Acquity UPLC BEH C18 sorbent column, 1.7- $\mu \mathrm{m}$ particles, $2.1 \times 100 \mathrm{~mm}$; Waters, Milford, MA), coupled to a mass spectrometer with a positive ion mode electrospray interface (4000 QTRAP; AB Sciex, Framingham, MA), and expressed in $\mathrm{ng} / \mathrm{mL}$ of plasma or $\mathrm{ng} / \mathrm{g}$ of tissue.

\section{CXCR4 Gene Sequencing Analysis}

After isolation of genomic DNA from CT-2A and GL261 glioma cells using the QIAmp DNA Blood Mini Kit (Qiagen Inc., Valencia, CA), Sanger sequencing of the PCR-amplified products of the CXCR4 gene locus was performed and analyzed by Genewiz LLC (South Plainfield, NJ). Briefly, the two exons of the CXCR4 gene of each glioma cell line were individually amplified by PCR using four pairs of primers:
Table 1 List of PCR Primers and Sequencing Primers Used for Sanger Sequencing of the Mouse CXCR4 Gene

\begin{tabular}{|c|c|c|}
\hline Exon & Primer name & Primer sequence \\
\hline \multicolumn{3}{|c|}{ PCR primers } \\
\hline \multicolumn{2}{|c|}{ Exon 1 CXCR4-Ex1-F } & $5^{\prime}$-TGGCGGAGGTTCCAACATTG-3' \\
\hline & CXCR4-Ex1-R & $5^{\prime}$ - $\overline{\text { CTCCCCCTATAGCCATGTTC }}-3^{\prime}$ \\
\hline \multicolumn{2}{|c|}{ Exon 2 CXCR4-Ex2-1-F } & $5^{\prime}$-TTGGAGTTTCCTGGGAAAGG $-3^{\prime}$ \\
\hline \multicolumn{2}{|c|}{ CXCR4-EX2-1-R } & $5^{\prime}-\overline{\text { TCAGGTATAGTCAGGAGGAG }}-3^{\prime}$ \\
\hline \multicolumn{2}{|r|}{ CXCR4-Ex2-2-F } & 5'-ACTGTCAACCTCTACAGCAG-3' \\
\hline \multicolumn{2}{|r|}{ CXCR4-Ex2-2-R } & $5^{\prime}$-TTTGGAAAGGATCTTGAGGC-3' \\
\hline \multicolumn{2}{|r|}{ CXCR4-Ex2-3-F } & $5^{\prime}$-CAAGTGGATCTCCATCACAG-3' \\
\hline \multicolumn{2}{|r|}{ CXCR4-Ex2-3-R } & 5'-CTGCCTAGACACTCATI \\
\hline \multicolumn{3}{|c|}{ Sequencing primers } \\
\hline \multicolumn{2}{|c|}{ Exon 1 CXCR4-Ex1-F } & $5^{\prime}$-TGGCGGAGGTTCCAACATTG-3' \\
\hline & CXCR4-Ex1-SeqR & $5^{\prime}-\overline{\text { TTCCCGCTCCTCCTTGTGAC }}-3^{\prime}$ \\
\hline \multirow[t]{6}{*}{ Exon 2} & CXCR4-Ex2-1-F & $5^{\prime}$-TTGGAGTTTCCTGGGAAAGG $-3{ }^{\prime}$ \\
\hline & CXCR4-EX2-1-R & $5^{\prime}$-TCAGGTATAGTCAGGAGGAG $-3^{\prime}$ \\
\hline & CXCR4-Ex2-2-F & 5'-ACTGTCAACCTCTACAGCAG-3' \\
\hline & CXCR4-EX2-2-R & 5'-TTTGGAAAGGATCTTGAGGC-3' \\
\hline & CXCR4-Ex2-3-F & 5'-CAAGTGGATCTCCATCACAG-3' \\
\hline & CXCR4-Ex2-3-SeqR & 5'-GTCTTTGCATAAGTGTTAGC-3' \\
\hline
\end{tabular}

Nucleotides which are underlined indicate noncoding regions.

one pair for the first exon and 350-bp upstream region and three pairs for the second exon (Table 1). Each amplicon was purified using ExoSAP-IT (Thermo Fisher Scientific, Waltham, MA) and subsequently sequenced in the forward and reverse directions using the BigDye Terminator Cycle Sequencing Kit (Thermo Fisher Scientific) on an ABI 3730 DNA Analyzer (Applied Biosystems, Foster City, CA). The sequences obtained were compared with the reference sequences for CXCR4 mRNA and CXCR4 gene locus of C57BL/6J mice (https://www.ncbi.nlm.nih.gov/nuccore; GenBank accession numbers NM_009911.3 and NC_ 000067.6, respectively) using SnapGene software version 2. 3.2 (GSL Biotech LLC, Chicago, IL). The threshold for single-nucleotide polymorphism detection was set to $10 \%$ of the major peak. All sequencing traces were of quality value $>41$ (probability of error, $<0.010 \%$ ).

\section{Western Blot Analysis}

The expression of CXCR4 protein in glioma cells was demonstrated by Western blotting, as previously described. ${ }^{22,23}$ Briefly, CT-2A and GL261 cells $\left(5 \times 10^{5} /\right.$ $10-\mathrm{cm}$ plates $)$ were incubated under normoxic $\left(21 \% \mathrm{O}_{2}\right)$ and hypoxic $\left[1 \% \mathrm{O}_{2}\right.$ in an incubator chamber (BillupsRothenberg, Del Mar, CA)] conditions for up to 24 hours and lysed in radioimmunoprecipitation assay buffer (SigmaAldrich) supplemented with complete protease inhibitor (Roche Diagnostics, Indianapolis, IN) and $2 \mathrm{mmol} / \mathrm{L} \mathrm{Na}$ orthovanadate (Sigma-Aldrich). Equal amounts of protein [40 to $60 \mu \mathrm{g}$, measured by micro bicinchoninic acid protein assay (Pierce Biotechnology, Rockford, IL)] in the presence of $5 \% \beta$-mercaptoethanol were resolved on $8 \%$ SDS-PAGE gels and transferred to Immobilon-P membranes (Millipore, Bedford, MA) by electroblotting at $4{ }^{\circ} \mathrm{C}$ overnight. Western 
blotting was performed using rabbit anti-murine CXCR4 (1:250 dilution, NB100-56437; Novus Biologicals, Littleton, $\mathrm{CO}$ ), rabbit anti-murine hypoxia-inducible factor (HIF)-1 $\alpha$ (1:1000 dilution, A300-286A; Bethyl Laboratories, Montgomery, TX), and rabbit anti-murine $\beta$-actin (1:5000 dilution, A2066; Sigma-Aldrich) antibodies. After incubation with horseradish peroxidase-conjugated enhanced chemiluminescence anti-rabbit IgG (1:5000 dilution; GE Health Care, Chalfont, UK), chemiluminescence was detected with SuperSignal West Pico (CXCR4 and $\beta$-actin) or Femto (HIF-1 $\alpha$ ) Substrate Kits (Thermo Fisher Scientific), and densitometry of the protein bands was performed using ImageJ software.

\section{CXCR4 Ligand Binding Assay}

A CXCR4 competitive binding assay (Tag-lite; Cisbio Bioassays, Codolet, France) based on time-resolved fluorescence resonance energy transfer as a readout for binding activity $^{44}$ was performed according to the manufacturer's instructions. Briefly, labeled CXCR4-expressing HEK293 cells (C1TT1CXCR4) were plated in 384-well microplates. A fixed concentration $(15 \mathrm{nmol} / \mathrm{L})$ of red-labeled fluorescent SDF- $1 \alpha$ ligand (L0012RED) was added to increasing concentrations of the CXCR4 antagonists POL5551 $\left(5 \times 10^{-11}\right.$ to $\left.5 \times 10^{-7} \mathrm{~mol} / \mathrm{L}\right)$ or AMD3100 $\left(5 \times 10^{-10}\right.$ to $5 \times 10^{-6}$ $\mathrm{mol} / \mathrm{L}$ ) diluted in Tag-lite buffer. After incubation for 3 hours at $4^{\circ} \mathrm{C}$, plates were read at the donor $(620 \mathrm{~nm})$ and acceptor $(665 \mathrm{~nm})$ emission wavelengths after excitation at $340 \mathrm{~nm}$ using a Victor 2V microplate reader (Perkin Elmer, Waltham, MA). The responses were normalized using controls without antagonist or with excess $(500 \mathrm{nmol} / \mathrm{L})$ of unlabeled SDF- $1 \alpha$ (100\% and $0 \%$ binding, respectively). The half-maximal inhibitory concentration $\left(\mathrm{IC}_{50}\right)$ for each compound tested was calculated using GraphPad Prism version 5.03 (GraphPad Software, La Jolla, CA).

\section{Intracellular Calcium Flux Assay}

Murine CXCR4-transfected 300-19 murine pre-B cells were labeled with Calcium 4 reagent (Molecular Devices, Sunnyvale, CA) in Hanks' balanced salt solution (without phenol red) containing $20 \mathrm{mmol} / \mathrm{L}$ HEPES and $0.1 \%$ bovine serum albumin at $37^{\circ} \mathrm{C}$ for 40 minutes, dispensed $\left(8 \times 10^{4} /\right.$ well) in black-wall 384-well microplates, centrifuged, and placed in a FLIPR 384 fluorometric imaging plate reader (Molecular Devices). After reading a 20-second baseline, the cells were stimulated with a fixed concentration $(10 \mathrm{nmol} / \mathrm{L})$ of SDF- $1 \alpha$ and treated with increasing concentrations of POL5551 or AMD3100 in Hanks' balanced salt solution containing $20 \mathrm{mmol} / \mathrm{L}$ HEPES and $0.1 \%$ bovine serum albumin at room temperature. Calcium flux signals were recorded for 200 seconds before and after addition of SDF$1 \alpha$ or CXCR 4 antagonists. The maximum and minimum signals were determined from control wells without CXCR4 antagonists or SDF- $1 \alpha$, respectively. The resulting percentage of inhibition of SDF- $1 \alpha$-induced calcium flux was used to calculate the $\mathrm{IC}_{50}$ values for POL5551 or AMD3100 using GraphPad Prism.

\section{Cytotoxicity Assay}

The cytotoxicity of POL5551 was determined by MTT assay. Briefly, CT-2A, GL261, and U87 glioma cells ( $2 \times 10^{4} /$ well) were cultured in DMEM with 10\% FBS in 96-well plates to reach $40 \%$ confluence at 24 hours and incubated in quadruplicate with various concentrations of POL5551 (1 nmol/L to 1 $\mu \mathrm{mol} / \mathrm{L}$ ) for an additional 16 hours. After removing the culture medium, MTT ( $0.5 \mathrm{mg} / \mathrm{mL}$; Sigma-Aldrich) in PBS was added and incubated at $37^{\circ} \mathrm{C}$ for 2 hours. After solubilization of the formazan product with $10 \%$ SDS in PBS and incubation at $37^{\circ} \mathrm{C}$ for 2 hours in the dark, the absorbance was recorded at $540 \mathrm{~nm}$ (test) and $690 \mathrm{~nm}$ (reference) using a SpectraMax M5 microplate reader (Molecular Devices), and the cellular viability was calculated as a percentage of controls.

\section{Cell Migration Assay}

The effect of POL5551 on glioma cell migration was evaluated under normoxic or hypoxic conditions using Boyden chamber assays, as previously described. ${ }^{22,23}$ Briefly, glioma cells cultured to $80 \%$ confluence were detached using Accutase (Innovative Cell Technologies, San Diego, CA) to minimize CXCR4 proteolysis, ${ }^{45}$ and cells $\left(5 \times 10^{4} /\right.$ well $)$ in $400 \mu \mathrm{L}$ DMEM with $1 \%$ FBS were seeded in triplicate in BioCoat polyethylene terephthalate filter inserts with $8-\mu \mathrm{m}$ porosity (354578; Corning, Lowell, MA) placed in 24-well plates containing $600 \mu \mathrm{L}$ DMEM with $1 \%$ FBS per well for 2 hours to allow cells to adhere. After replacing the upper chamber medium with DMEM containing 1\% FBS and various concentrations of POL5551 (0 to $500 \mathrm{nmol} / \mathrm{L}$ ), cells were allowed to migrate for 16 hours in the absence or presence of murine $\mathrm{SDF}-1 \alpha$ [0 or $50 \mathrm{nmol} / \mathrm{L}$ (equivalent to $400 \mathrm{ng} / \mathrm{mL}$ ) in the lower chamber] under normoxic or hypoxic conditions at $37^{\circ} \mathrm{C}$. After incubation, the inserts were washed twice with PBS, fixed with $100 \%$ methanol, and stained with $1 \%$ toluidine blue in $1 \%$ borax, and the number of migrated cells on the entire lower surface was counted using an Eclipse inverted microscope (Nikon Instruments, Melville, NY). To assess whether cellular proliferation contributed to the observed changes, cells were allowed to migrate in the absence or presence of the ribonucleotide reductase inhibitor hydroxyurea (10 mmol/L; Sigma-Aldrich) for 16 hours, ${ }^{46}$ and the numbers of migrated cells were compared.

\section{Statistical Analysis}

Continuous measures were expressed as means \pm SEM and tested for normality using D'Agostino-Pearson K2 and Shapiro-Wilk tests. Because of the observed skewness of the tumor volume and invasiveness data, these data were logarithmically transformed before statistical analysis. 

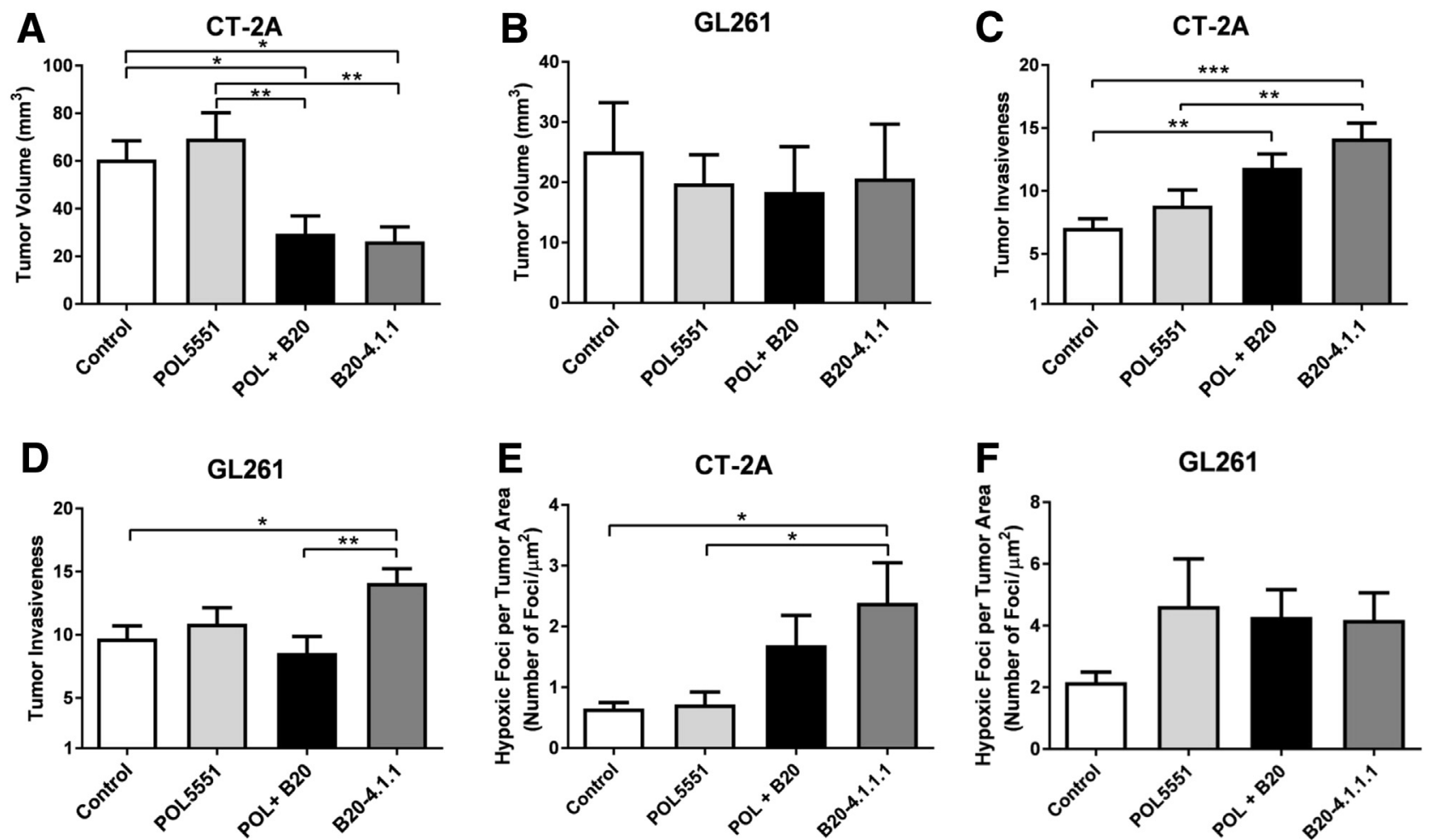

Figure 1 Tumor volume, invasiveness, and hypoxic foci in glioma-bearing mice treated with CXCR4 antagonist POL5551 (POL) and/or anti-murine VEGF antibody B20-4.1.1 (B20). Beginning on day 14 after tumor implantation, mice bearing CT-2A or GL261 glioma were administered P0L5551, B20-4.1.1, and/or vehicles. On day 26 , the brains were harvested and tissue sections were stained with hematoxylin and eosin to measure the tumor volume (A and $\mathbf{B})$ and invasiveness ( $\mathbf{C}$ and $\mathbf{D}$ ) or immunostained to count the number of hypoxic foci (E and $\mathbf{F}$ ). Tumor invasiveness (INV) was calculated using the equation, $\mathrm{INV}=\mathrm{P} / \sqrt{4 \pi \mathrm{S}}$, where $\mathrm{P}$ is the perimeter and $\mathrm{S}$ is the surface area of the tumor; a noninvasive spherical tumor would have INV $=1.0$, whereas INV is $>1.0$ for a tumor with increasingly irregular/invasive borders. The results were analyzed by analysis of variance. Data are expressed as means \pm SEM. $n=9$ to 10 per group $(\mathbf{A}-\mathbf{F}) .{ }^{*} P<0.05,{ }^{* *} P<0.01$, and ${ }^{* * *} P<0.001$.

Statistical differences between the means of groups were evaluated by one- or two-way analysis of variance, followed by the Tukey post hoc test. For the Iba1 and nestin score rank analysis, these categorical data were expressed as mean ranks $\pm 95 \%$ confidence intervals, and the differences between the mean ranks of groups were evaluated by KruskalWallis test, followed by Dunn post hoc test. All tests were two sided, and $P \leq 0.05$ was considered statistically significant. All statistical analyses were performed using GraphPad Prism version 6.

\section{Results}

Tumor Volume and Invasiveness in Glioma-Bearing Mice Treated with POL5551 Alone and in Combination with B20-4.1.1

In CT-2A glioma-bearing mice, treatment with anti-VEGF antibody B20-4.1.1 alone significantly reduced the tumor volume compared with controls (by $57 \%, P<0.01$ ) or POL5551 alone (by $62 \%, P<0.01$ ). The combination of POL5551 with B20-4.1.1 did not decrease the tumor volume further (ie, by $60 \%, P<0.01$ ) (Figure $1 \mathrm{~A}$ ). No significant effect between treatment with B20-4.1.1 alone or in combination with POL5551 was apparent on GL261 tumor volume either (Figure 1B). As seen in the latter, anti-VEGF agents have been found to not always produce a significant alteration of tumor size. ${ }^{47}$

In both CT-2A and GL261 glioma, treatment with B20-4.1.1 alone increased tumor invasiveness compared to controls [twofold $(P<0.001)$ and 1.4-fold $(P<0.05)$, respectively] (Figure 1, C and D), also consistent with observations in GBM patients treated with bevacizumab. ${ }^{1-3}$ When POL5551 was combined with B20-4.1.1, tumor invasiveness was reduced compared with B20-4.1.1 alone in GL261 glioma (by 39\%, $P<0.01$ ) (Figure $1 \mathrm{D}$ and Supplemental Figure S1, A-D). A lesser reduction (16.4\%) of CT-2A glioma invasiveness was measured compared with B20-4.1.1 alone (Figure 1C and Figure 2, A-D). The presence of single glioma cell infiltration into brain parenchyma was not assessed in the present study, but has been demonstrated to be present at least in a GL261 glioma model using green fluorescent protein-labeled GL261 cells. ${ }^{34}$

Tumor Hypoxia, Vascular Density, Cell Proliferation, and Apoptosis in Glioma-Bearing Mice Treated with P0L5551 Alone and in Combination with B20-4.1.1

Administration of B20-4.1.1 alone induced more tumor hypoxic foci compared to controls in CT-2A glioma 

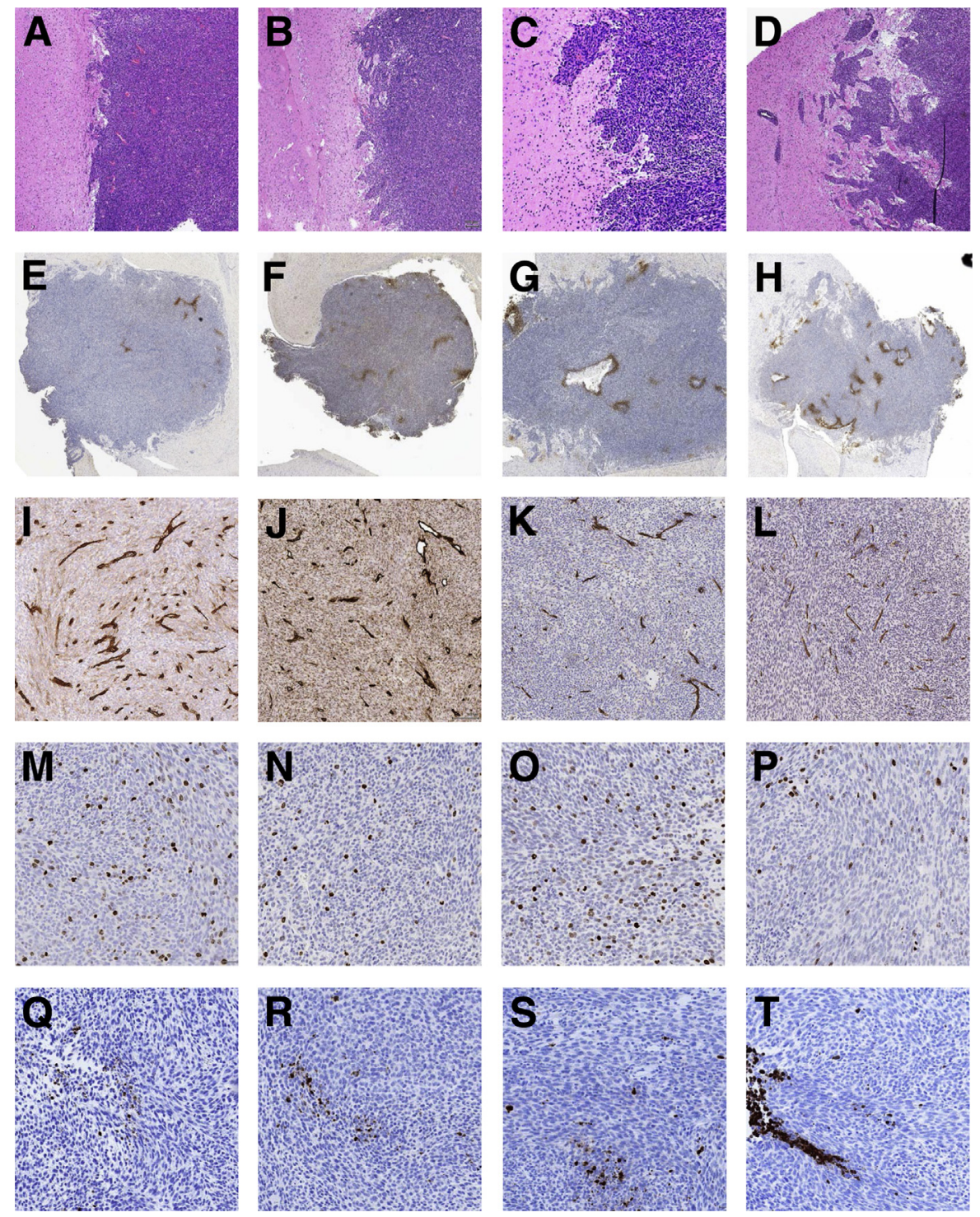

Figure 2 Representative immunohistopathologic images of tumor invasion, hypoxic foci, vascular density, proliferation, and apoptosis in CT-2A glioma tumors. Tissue sections from CT-2A glioma-bearing mice treated with vehicles (first column), P0L5551 alone (second column), P0L5551 and B20-4.1.1 (third column), or B20-4.1.1 alone (fourth column) were stained with hematoxylin and eosin to show tumor invasive borders (A-D) or immunostained to demonstrate the presence of hypoxic foci $(\mathbf{E}-\mathbf{H})$, vascular density $(\mathbf{I}-\mathbf{L})$, cellular proliferation $(\mathbf{M}-\mathbf{P})$, and apoptosis $(\mathbf{Q}-\mathbf{T})$. Original magnification: $\times 10$ $(\mathbf{A}-\mathbf{D}$ and $\mathbf{I}-\mathbf{L}) ; \times 2(\mathbf{E}-\mathbf{H}) ; \times 20(\mathbf{M}-\mathbf{T})$.

(4.1-fold, $P<0.05)$ and to a lesser extent in GL261 glioma (1.9-fold) (Figure 1, E and F). However, B20-4.1.1 alone only slightly reduced (by $16 \%$ to $28 \%$ ) the vascular density, measured as $\mathrm{CD} 105^{+}$endothelial cell density in both models compared to controls (Figure 3, A and B). These data are consistent with those previously reported for GL261 tumor after a more frequent dosing of B20-4.1.1 (5 $\mathrm{mg} / \mathrm{kg}$ i.p. three times/week). ${ }^{48}$ Although POL5551 combined with B20-4.1.1 did not significantly affect the number of hypoxic foci induced by B20-4.1.1 in both tumors (Figure 1, E and F), the combination of POL5551 with B204.1 .1 led to approximately a $49 \%$ reduction $(P>0.05)$ of the vascular density in both models compared to controls (Figure 3, A and B). Representative images of hypoxic foci and vascular density of glioma-bearing mice treated with POL5551 and/or B20-4.1.1 are shown for CT-2A (Figure 2, E-L) and GL261 gliomas (Supplemental Figure S1, E-L). Considering tumor proliferation and apoptosis, B20-4.1.1 alone also inhibited tumor proliferation significantly $(67 \%$, $P<0.05$ ) in GL261 glioma (Figure 3D) compared to controls. POL5551 alone similarly attenuated tumor proliferation by $56 \%(P>0.05)$ in GL261 glioma (Figure 3D), a result consistent with the known stimulatory effect of SDF- $1 \alpha$ on glioma cell proliferation ${ }^{49}$; the combination treatment yielded only a small additional benefit (ie, a $67 \%$ reduction, $P>0.05$ ). However, combined treatment significantly increased apoptosis in GL261 glioma compared to controls (2.5-fold, $P<0.05$ ) (Figure 3F), a 

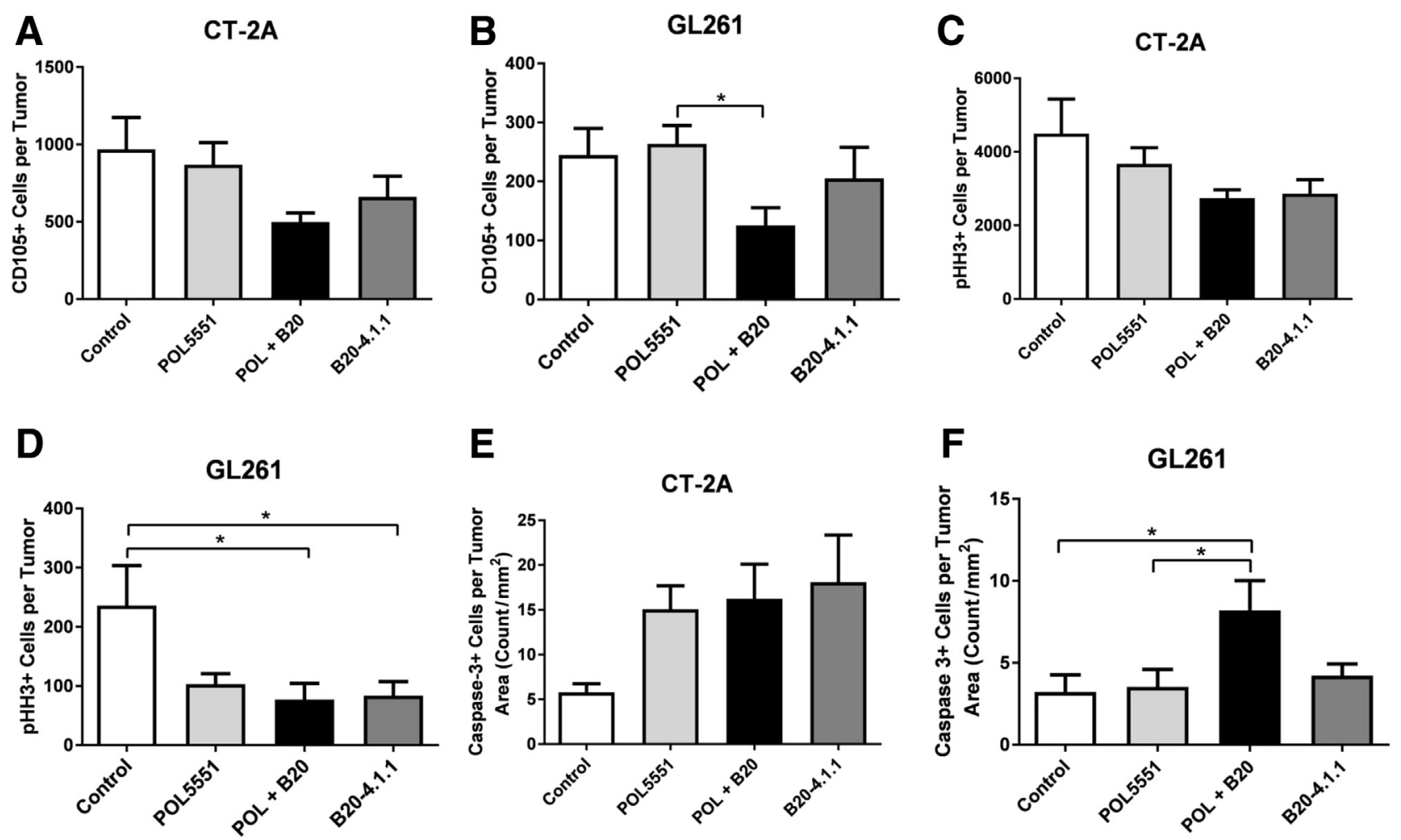

Figure 3 Tumor vascular density, cell proliferation, and apoptosis in glioma-bearing mice treated with P0L5551 (POL), B20-4.1.1 (B20), and/or vehicles. Brain tissues from the same glioma-bearing mice were immunostained to measure vascular density (CD105; $\mathbf{A}$ and $\mathbf{B})$, tumor cell proliferation (pHH3; $\mathbf{C}$ and $\mathbf{D})$, and apoptosis (caspase 3; E and $\mathbf{F}$ ), and positively stained cells were enumerated per section. The results were analyzed by analysis of variance. Data are expressed as means \pm SEM. ${ }^{*} P<0.05$.

finding in agreement with the known stimulation of glioma cell survival by SDF- $1 \alpha .^{49}$ Representative images of tumor proliferation and apoptosis of glioma-bearing mice treated with POL5551 and/or B20-4.1.1 are shown for CT-2A (Figure 2, M-T) and GL261 gliomas (Supplemental Figure S1, M-T). Because CT-2A tumors did not show statistically significant changes in proliferation and apoptosis (Figure 3, C and E) that could account for reductions in tumor volumes after B20-4.1.1 or combined therapy (Figure 1A), we determined whether the tumor content of other major cell types changed.

Tumor Macrophage/Microglial and Stem Cell Fractions in Glioma-Bearing Mice Treated with P0L5551 Alone and Combined with B20-4.1.1

Infiltrating most human glioma tumors, macrophage/ microglial cells comprise up to $30 \%$ of the tumor mass. ${ }^{10}$ In the CT-2A glioma model, combined treatment reduced the number of Iba1-positive macrophage/microglial cells by $54 \%(P<0.05)$ compared to POL5551 alone (Figure 4A and Figure 5, B and C); this correlated with similar changes (57\% reduction, $P<0.01$ ) in tumor volume (Figure $1 \mathrm{~A}$ ). In mice treated with B20-4.1.1 alone or in combination with POL5551, Iba1-positive cells were noted predominantly in areas with heightened tumor invasion (Figure 5, C and D) compared to controls, which corroborates the pattern of Iba1 immunopositivity seen in U87 glioma treated with the soluble VEGF decoy receptor drug aflibercept. ${ }^{39}$ Considering tumor-initiating GSCs that also comprise a significant portion of the tumor, ${ }^{42,50}$ the number of nestin-positive cells was reduced by $69 \%(P<0.001)$ by POL5551 alone compared to B20-4.1.1 alone in the CT-2A model (Figure 4C), a finding that validates the subjective reduction of nestin-positive cells seen in U87 glioma treated with POL5551. ${ }^{51}$ In GL261 glioma treated with B20-4.1.1 and/ or POL5551, the preferential distribution of Iba1 immunopositivity at the tumor border or center was also seen, but lesser effects on Ibal and nestin were observed in that model (Figure 4, B and D). Representative images of tumor MGCs and tumor-initiating GSCs of glioma-bearing mice treated with POL5551 and/or B20-4.1.1 are shown for CT-2A (Figure 5) and GL261 glioma (Supplemental Figure S2). Treatment-induced loss of microglia/macrophage and/or stem cell tumor content appears to reflect more closely the changes in tumor volumes than tumor proliferation and apoptosis.

\section{CXCR4 Gene Mutation Analysis in Glioma Cells}

Because CT-2A and GL261 tumors did not always show similar responses to POL5551 and B20-4.1.1, we 


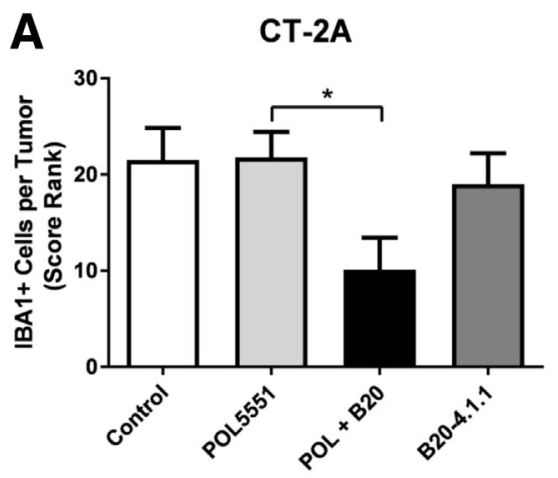

C

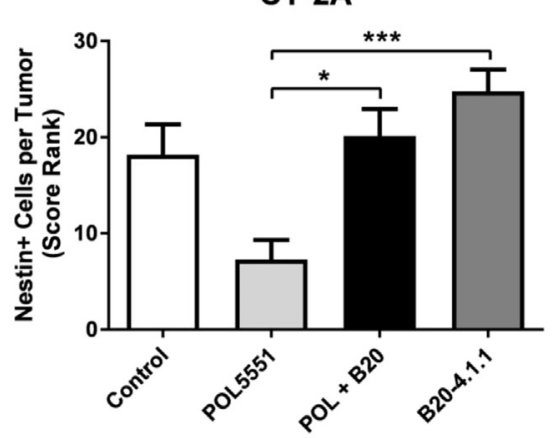

B

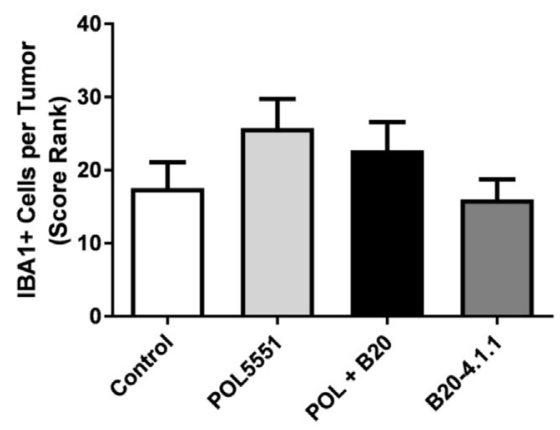

D

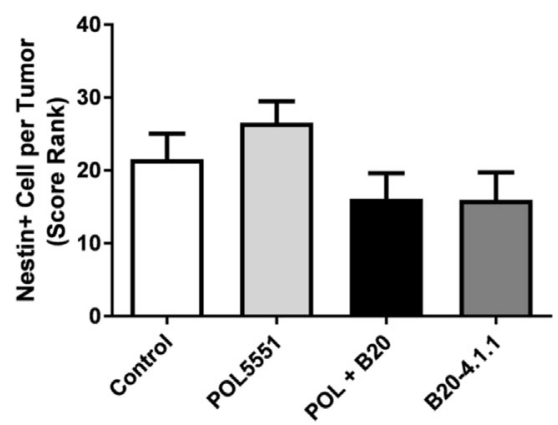

Figure 4 Tumor macrophage/microglial cells (MGCs) and glioma stem cells (GSCs) in gliomabearing mice treated with POL5551 (POL), B20-4.1.1 (B20), and/or vehicles. Brain tissues from the same glioma-bearing animals were immunostained to measure tumor MGCs (Iba1; $\mathbf{A}$ and $\mathbf{B}$ ) and GSCs (nestin; C and D). Positively stained cells per section were scored on a 1 to 4 scale ( 1 if $<1 \%, 2$ if $1 \%$ to $10 \%, 3$ if $11 \%$ to $50 \%$, and 4 if $51 \%$ to $100 \%$ ). The results were analyzed by Kruskal-Wallis test. Data are expressed as mean score ranks $\pm 95 \%$ confidence intervals. ${ }^{*} P<0.05,{ }^{* * *} P<0.001$ determined whether some of these differences resulted from CXCR4 mutations. A common $C X C R 4$ polymorphism (rs2228014 $C / C$ genotype) has recently been found to predict progression-free survival in metastatic colorectal cancer patients treated with first-line bevacizumab-based chemotherapy. ${ }^{52}$ The nucleotide sequence of the CXCR4 gene and 350-bp upstream regulatory region from CT-2A and GL261 glioma genomic DNA was analyzed by Sanger sequencing of PCR-amplified products, but no CXCR4 mutations were identified in glioma cells that could alter their function or response to the treatments (Figure 6 and Table 1).
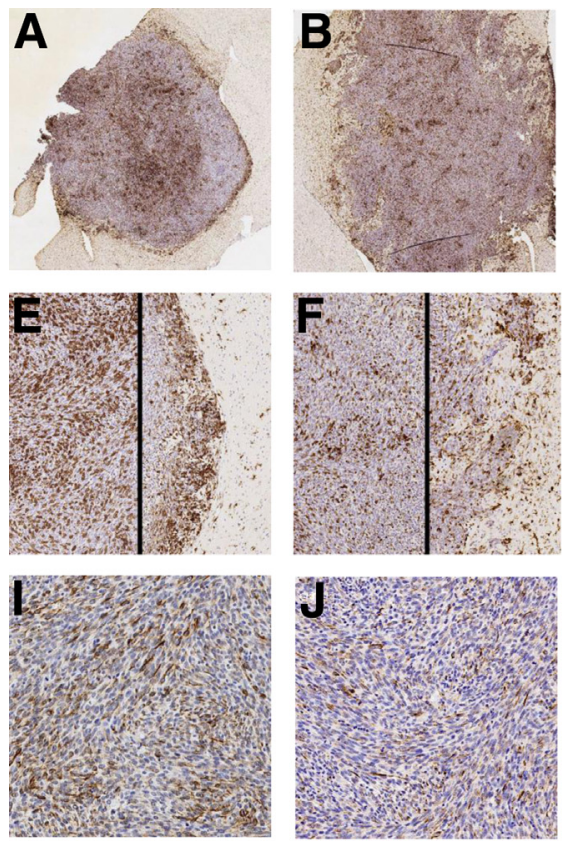
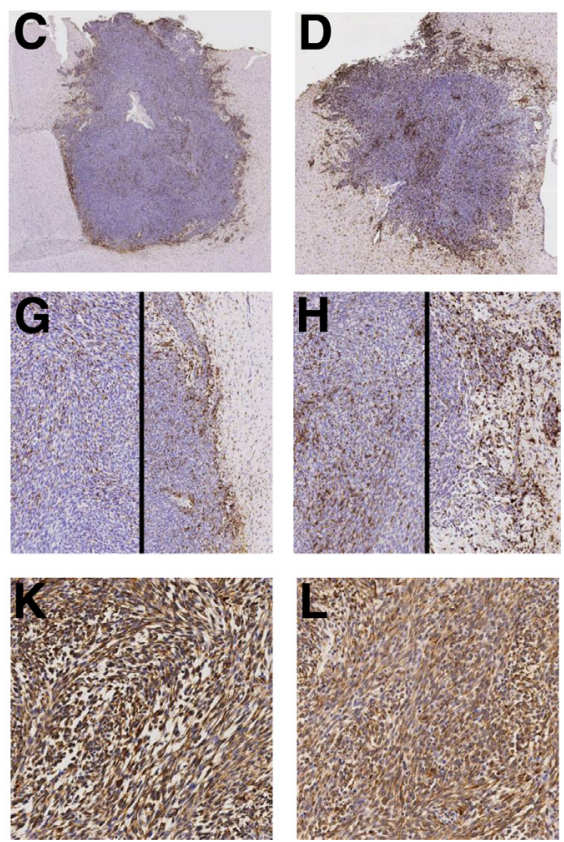
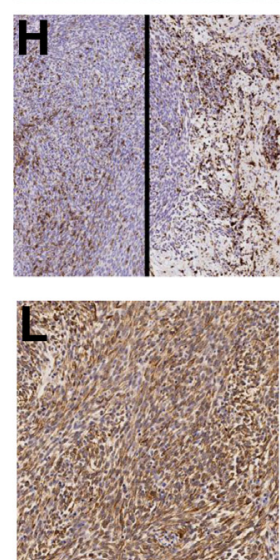

Figure 5 Representative immunohistopathologic images of macrophage/microglial cells (MGCs) and glioma stem cells (GSCs) in CT-2A glioma tumors. Tissue sections from CT-2A gliomabearing mice treated with vehicles (first column), POL5551 alone (second column), POL5551 and B20-4.1.1 (third column), or B20-4.1.1 alone (fourth column) were immunostained to demonstrate the presence of Iba1-positive MGCs [shown at two magnifications, low $(\mathbf{A}-\mathbf{D})$ and high $(\mathbf{E}-\mathbf{H})$, the latter with two subpanels separated by a black line showing the tumor center (left sides) and tumor periphery (right sides)] and nestin-positive GSCs $(\mathbf{I}-\mathbf{L})$. Original magnification: $\times 3.5(\mathbf{A}-\mathbf{D})$; $\times 20(\mathrm{E}-\mathrm{L})$. 


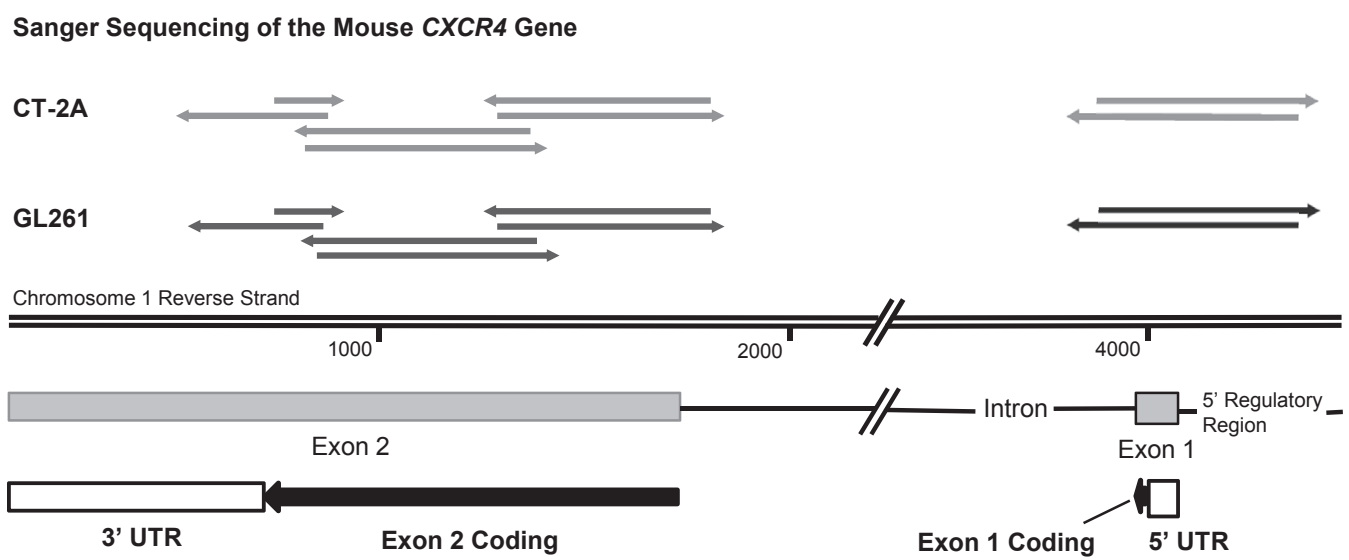

Figure 6 Schematic diagram of the mouse CXCR4 gene locus on chromosome 1 showing the location of the two exons, coding regions, $3^{\prime}$ - and $5^{\prime}$-unstranslated regions ( $3^{\prime}$ UTR and $5^{\prime} U T R$, respectively), and $5^{\prime}$ regulatory region. Also indicated is the alignment of the Sanger sequencing reads for CT-2A and GL261 genomic DNA with mouse genome GRCm38/mm10. Each pair of primers for exon 2 overlapped by 100 bp to enhance the alignment of DNA sequences.

Pharmacokinetics of POL5551 in Glioma-Bearing Mice Treated with POL5551 Alone and Combined with B20-4.1.1

In naïve mice, administration of POL5551 (5 mg/kg s.c.) resulted in a maximal plasma concentration at 1 hour after administration of $5800 \mathrm{ng} / \mathrm{mL}(2.96 \mu \mathrm{mol} / \mathrm{L})$ and a half-life of 0.6 hours. A model-predicted exposure profile is shown in Supplemental Figure S3. We next measured the concentration of POL5551 in the plasma and brain tissues (tumor tissue, brain adjacent to tumor, and contralateral brain) of glioma-bearing mice treated or not with B20-4.1.1. In a first experiment, CT2A glioma-bearing mice received a single dose of POL5551 at various times before sacrifice (Figure 7). At the 30-minute time point, the concentration of POL5551 was higher in tumor tissues $(286 \pm 38 \mathrm{ng} / \mathrm{g})$ than in brain adjacent to tumor (48 $\pm 9 \mathrm{ng} / \mathrm{g}$ ) or contralateral brain $(53 \pm 23 \mathrm{ng} / \mathrm{g})$, consistent with the concentrations of POL5551 detected in U87 glioma. ${ }^{51}$ Administration of B20-4.1.1 reduced the concentration of POL5551 in tumors by 4.8 -fold $(P<0.01)$ at 30 minutes, despite comparable plasma levels (Figure 7), suggesting that this anti-VEGF agent decreased the delivery of POL5551 to tumors. In an experiment in which CT-2A glioma-bearing mice were administered POL5551 repeatedly for 2 weeks, the tumor concentration of POL5551 (205 $\pm 34 \mathrm{ng} / \mathrm{g})$ at 30 minutes after the final dose was similar to that measured after a single dose of POL5551 $(P>0.05)$ (Supplemental Figure S4). However, the concentration of POL5551 (134 $\pm 26 \mathrm{ng} / \mathrm{g})$ achieved in tumors treated with B20-4.1.1 was 2.2-fold higher than that ( $60 \pm 15$ $\mathrm{ng} / \mathrm{g}$ ) after a single dose of POL5551 at 30 minutes, suggesting a cumulative effect of repeated POL5551 in the setting of VEGF inhibition.

Expression of CXCR4, and the Effect of POL5551 on CXCR4 Ligand Binding, Glioma Cell Viability, and Migration in Vitro

In a time-resolved fluorescence resonance energy transfer CXCR4 ligand binding assay, POL5551 completely displaced labeled SDF-1 $\alpha$ with an $\mathrm{IC}_{50}$ of $2.68 \mathrm{nmol} / \mathrm{L}$ (Figure $8 \mathrm{~A}$ ). In the same assay, the $\mathrm{IC}_{50}$ of $\mathrm{AMD} 3100$ was $>100$-fold higher (388 nmol/L). In addition, in Calcium 4 reagent-labeled CXCR4-transfected murine 300-19 pre-B cells, POL5551 completely inhibited the stimulatory effect of $\mathrm{SDF}-1 \alpha$ with an $\mathrm{IC}_{50}$ of $0.31 \mathrm{nmol} / \mathrm{L}$ compared to $63.6 \mathrm{nmol} / \mathrm{L}$ for AMD3100 (Supplemental Figure S5). These results with murine CXCR4-transfected cells are likely to be applicable to both CT-2A and GL261 cells given the wild-type $C X C R 4$ genotype in these murine glioma cell lines (Figure 6). Similar potency $\left(\mathrm{IC}_{50}\right)$ values of 1.7 and $495 \mathrm{nmol} / \mathrm{L}$ have been reported in a comparison of POL5551- and AMD3100-mediated inhibition of cellular $\mathrm{Ca}^{2+}$ flux in hematopoietic stem/progenitor cells, respectively. ${ }^{31}$ The high binding affinity of POL5551 to CXCR4 suggests that the concentrations of POL5551 (30 to 150 $\mathrm{nmol} / \mathrm{L}$ ) measured in tumor and normal tissues (Figure 7 and Supplemental Figure S4) were likely sufficient to account for its biological effects in vivo.

We used hypoxic conditions in vitro to simulate the hypoxic environment associated with intracerebral glioma in vivo. As we previously reported in human glioma cells, ${ }^{22,23}$ HIF- $1 \alpha$-regulated CXCR4 protein was constitutively expressed at low levels under normoxia and induced threefold after 18 to 24 hours of exposure to hypoxia in CT-2A cells, and twofold after 16 hours of exposure to hypoxia in GL261 cells (Figure 8B). The presence of dual bands for HIF-1 $\alpha$ and CXCR4, as we have previously reported, ${ }^{22}$ may reflect the detection of constitutive and inducible forms of HIF- $1 \alpha(115$ and $120 \mathrm{kDa}$ ), according to Bethyl Laboratories, and the formation of glycosylated isoforms of CXCR4 (42 and $49 \mathrm{kDa}),{ }^{53}$ respectively. The effects of POL5551 do not appear to be because of direct cytotoxicity as incubation with various concentrations of POL5551 $(1 \mathrm{nmol} / \mathrm{L}$ to $1 \mu \mathrm{mol} / \mathrm{L})$ had little effect on the viability of CT-2A, GL261, and U87 glioma cells (Figure 8C), in agreement with data obtained in adherent cultures of breast cancer cells treated with POL5551. ${ }^{54}$ In Boyden chamber assays, increasing concentrations of 

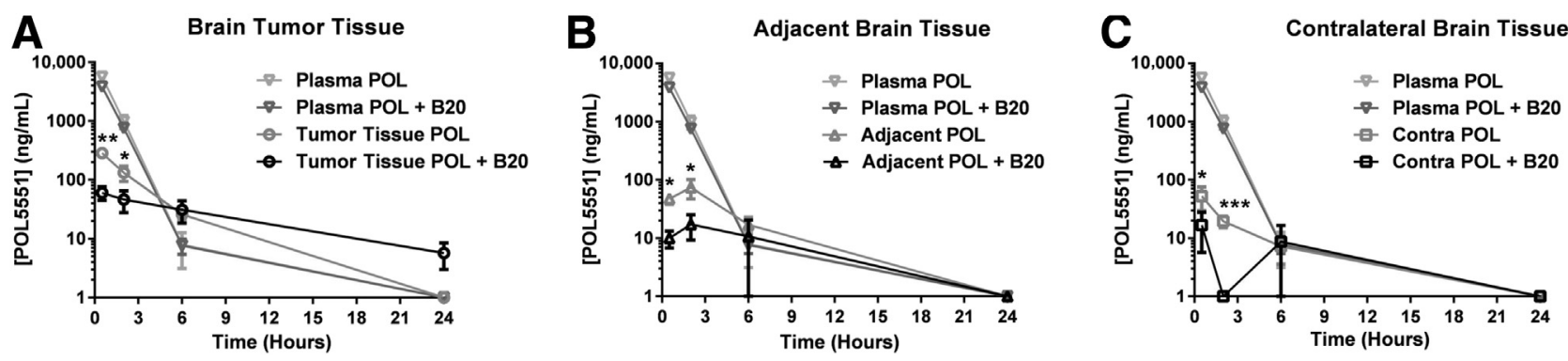

Figure 7 Plasma and brain tissue concentrations of P0L5551 (POL) after a single dose of P0L5551 or in combination with repeated B20-4.1.1 (B20) administration in CT-2A glioma-bearing mice. Beginning on day 14 after implantation, mice were administered B20-4.1.1 or vehicles for 12 days. On day 26 after a single dose of POL5551 (5 mg/kg s.c.), 0.5, 2, 6, or 24 hours before sacrifice, plasma was collected and the brains were dissected into tumor tissue (A), brain adjacent to tumor (B), and contralateral brain (C) to determine the concentration of P0L5551 in plasma $(\mathrm{ng} / \mathrm{mL})$ and brain tissue (ng/g). The results were analyzed by analysis of variance. Data are expressed as means \pm SEM. $n=4$ per group $(\mathbf{A}-\mathbf{C}) .{ }^{*} P<0.05,{ }^{* *} P<0.01$, and ${ }^{* * * P} P 0.001$.

POL5551 led to a gradual decrease in the rate of migration of glioma cells, requiring only 10 to $50 \mathrm{nmol} / \mathrm{L}$ for GL261 cells compared to 100 to $500 \mathrm{nmol} / \mathrm{L}$ for CT-2A cells (Figure 8, D-F), consistent with the inhibitory effect of POL5551 on the migration of breast cancer cells. ${ }^{54}$ The apparently greater sensitivity of GL261 cell migration to POL5551 is consistent with the larger inhibitory effect of POL5551 on the invasiveness of GL261 glioma in vivo compared to CT-2A glioma (Figure 1, C and D). The migration of CT-2A (Figure 8, D and F) and GL261 cells (Figure 8E) increased approximately twofold under 24-hour hypoxic conditions $(P<0.001)$ and to a lesser extent in response to SDF-1 $\alpha$. The higher concentration of POL5551 needed to inhibit CT-2A cell migration after hypoxic exposure $(500 \mathrm{nmol} / \mathrm{L})$ compared to normoxia $(100 \mathrm{nmol} / \mathrm{L})$ is consistent with a concurrent induction of CXCR4 on
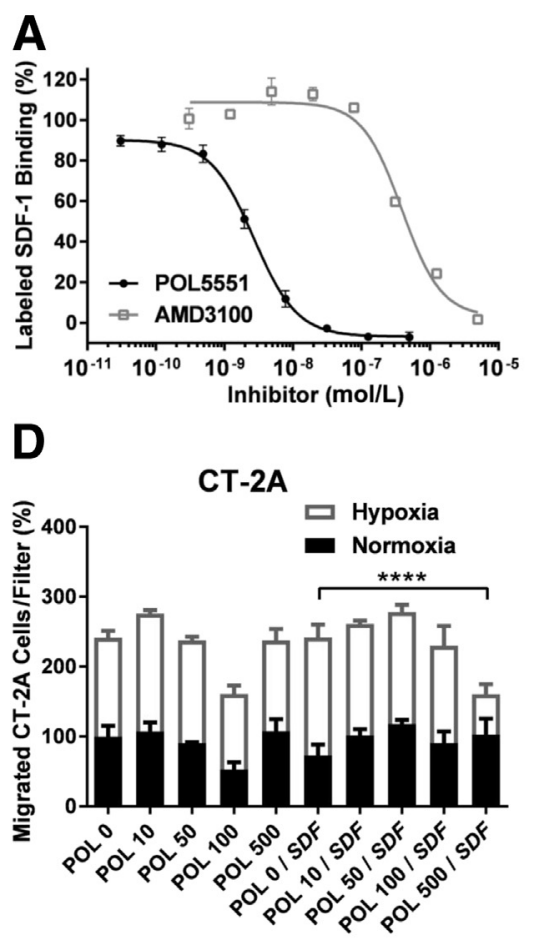
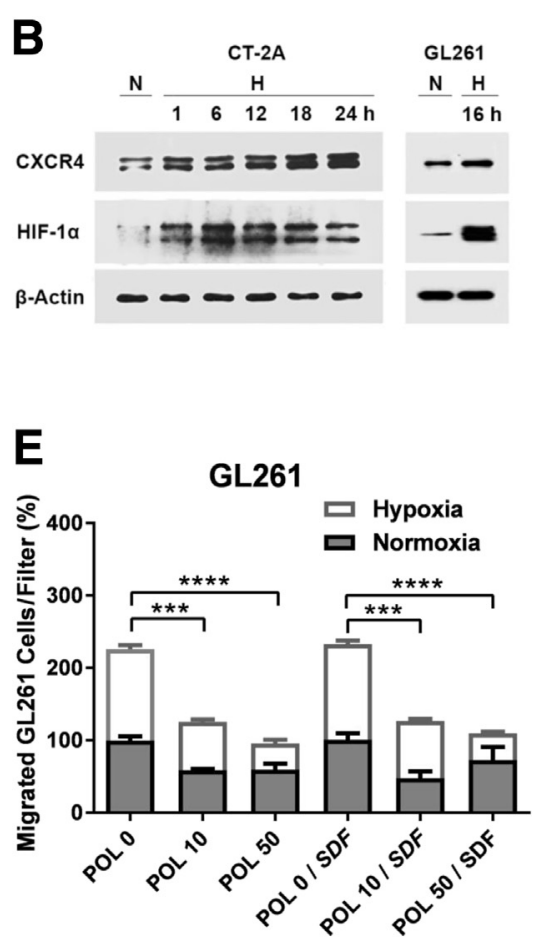

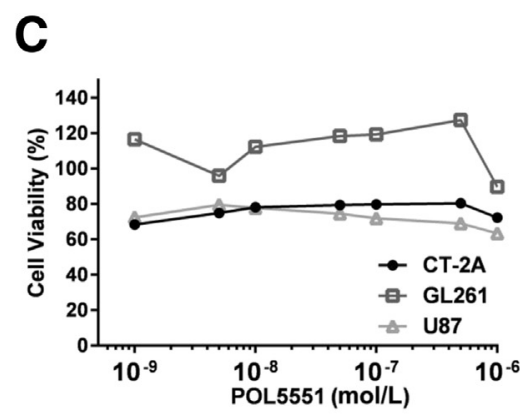

$\mathbf{F}$

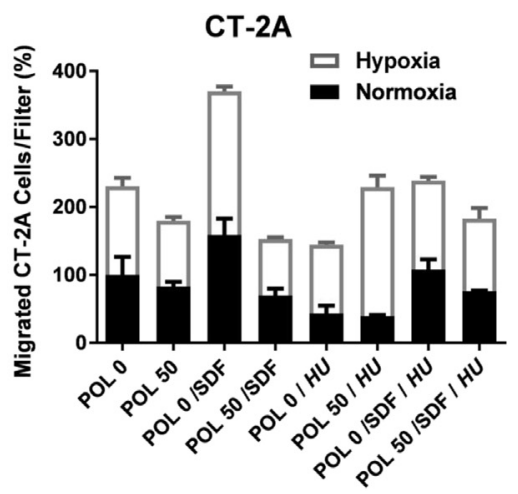

Figure 8 Expression of CXCR4, and effect of POL5551 on CXCR4 ligand binding, cell viability, and migration in glioma cells in vitro. A: Using the Tag-lite CXCR4 ligand binding assay, CXCR4-expressing HEK293 cells were incubated with increasing concentrations of POL5551 or AMD3100 in the presence of a fixed concentration of fluorescent SDF- $1 \alpha$; the normalized responses were plotted, and the half-maximal inhibitory concentration was calculated. B: CT-2A and GL261 cells were both incubated under normoxic $(\mathrm{N})$ and hypoxic $\left(\mathrm{H} ; 1 \% \mathrm{O}_{2}\right)$ conditions for up to 24 hours and for 16 hours, respectively, and the protein expression of CXCR4, HIF-1 $\alpha$, and $\beta$-actin was determined by Western blot analysis. C: CT-2A, GL261, and U87 glioma cells were incubated in quadruplicate with POL5551 ( $1 \mathrm{nmol} / \mathrm{L}$ to $1 \mu \mathrm{mol} / \mathrm{L})$ for 16 hours, and cell viability was assessed by MTT assay. D and E: In a Boyden chamber assay, CT-2A and GL261 cells were incubated in triplicate with POL5551 ( 0 to $500 \mathrm{nmol} / \mathrm{L}$ ) under normoxic and hypoxic conditions and allowed to migrate in the absence or presence of an SDF- $1 \alpha$ gradient $(50 \mathrm{nmol} / \mathrm{L})$ for 16 hours, after which the number of migrated cells was counted. F: To assess whether cellular proliferation contributed to the observed changes, cells were allowed to migrate in the presence of $10 \mathrm{mmol} / \mathrm{L}$ hydroxyurea for 16 hours. The results were analyzed by analysis of variance. Data are expressed as means $\pm \operatorname{SEM}(\mathbf{A}$ and $\mathbf{C}-\mathbf{F})$. ${ }^{* * * P}<0.001,{ }^{* * * * P}<0.0001$. 
glioma cell surface by hypoxia (Figure 8B). Overall, POL5551 reduced hypoxia- and SDF- $1 \alpha$-mediated migration dose-dependently in vitro, consistent with the inhibitory effect of POL5551 on the invasiveness of glioma cells in vivo. The migratory rate of CT-2A glioma cells treated with POL5551 was unchanged in the presence of the cytostatic drug hydroxyurea (Figure $8 \mathrm{~F}$ ), indicating that the effect of POL5551 on migration did not result from concurrent inhibition of cell proliferation.

\section{Discussion}

Preclinical studies suggest that combining antiangiogenic therapy with inhibitors targeting the tumor invasive phenotype could be a promising approach to overcoming cancer resistance to antiangiogenic therapy. ${ }^{11,12}$ Because enhanced tumor hypoxia during bevacizumab resistance is associated with increased SDF-1 $\alpha$ receptor CXCR4 expression on invading tumor, tumor-initiating GSCs, and tumor-associated MGCs, we chose to target CXCR4 using a highly potent PEM antagonist, POL5551. In novel immunocompetent mouse glioma models of antiangiogenic therapy, POL5551 achieved higher concentrations in intracranial glioma tumors than normal brain tissues, and reduced glioma invasion by inhibiting hypoxia-induced glioma migration, and the populations of GSCs and MGCs known to promote glioma proliferation and invasion, compared to controls. Our study differs from a previous study ${ }^{51}$ by the use of syngeneic invasive CT-2A and GL261 glioma $^{23,33,41}$ in immunocompetent mouse models (as opposed to minimally invasive U87 cells in nude mice). In addition, we have used B20-4.1.1, an anti-murine VEGF antibody comparable to BEV (both produced by Genentech Inc.), and demonstrated, for the first time, that a low dose $(5 \mathrm{mg} / \mathrm{kg})$ of POL5551 diminished B20-4.1.1-induced glioma invasion and glioma-associated MGCs, which are known to promote glioma invasion ${ }^{39}$ and participate in glioma-elicited immunosuppression. ${ }^{55,56}$

In malignant glioma, chronic exposure of tumor tissues to low oxygen tension produces necrotic areas surrounded by hypoxic pseudopalisading tumor cells that trigger HIF$1 \alpha$-regulated cellular processes, such as tumor invasion and angiogenesis. ${ }^{4,22,23}$ Among these HIF- $1 \alpha$-regulated events, we have demonstrated that hypoxia-induced expression of CXCR4 in pseudopalisading glioma cells promotes their migration at the invasive edges toward SDF- $1 \alpha$-secreting neurons and blood vessels. ${ }^{22,23}$ Consistent with our reports, distant glioma recurrence $(>4 \mathrm{~cm}$ from the margin of the original tumor) after total resection was found to be closely associated with high levels of SDF- $1 \alpha$ and CXCR4 expression in glioma tissues. ${ }^{21}$ Similarly, hypoxia-induced migration of neural stem cells to the glioma site is mediated by HIF- $1 \alpha$-dependent upregulation of SDF-1 $\alpha /$ CXCR4, VEGF/VEGF receptor 2, hepatocyte growth factor/c-MET, and urokinase-type plasminogen activator and its receptor. ${ }^{25}$ Hypoxia also favors microglia migration via enhanced CXCR4 expression., ${ }^{9,10}$ Inhibition of SDF-1 $\alpha /$ CXCR4 signaling has been found to reduce brain tumor growth or recurrence, ${ }^{28,29}$ the viability and number of GSCs, ${ }^{28,30}$ and the recruitment of glioma-associated MGCs. ${ }^{9,10}$ In our study, potent CXCR4 inhibition with POL5551 disrupted the interactions between cancer cells and their environment by reducing the invasiveness of glioma cells through a direct effect on glioma cell migration rather than an antiproliferative effect.

In GBMs, the uptake of drugs from the systemic circulation may be facilitated by the increased permeability of the blood-brain barrier associated with the pathologically structured microvessels and expression of VEGF and other angiogenic factors. ${ }^{4,5}$ The capacity of POL5551 (approximately $2 \mathrm{KDa}$ ) to cross this disrupted barrier and reach a high concentration in glioma tissue is evidenced by the lower tumor concentration of POL5551 in B20-4.1.1-treated mice, possibly because of transient vascular normalization ${ }^{16}$ during antiangiogenic therapy. Although B20-4.1.1 only slightly reduced the vascular density in our glioma models, the lower number of tumor hypoxic foci may reflect other effects that we did not examine, such as blood vessel lumen size, blood flow, hemorrhage, and/or thrombosis.

Recent advances in the classification of tumors of the central nervous system have demonstrated that different genetic subtypes of morphologically identical tumors have different natural histories and may differ significantly in their responses to treatment. ${ }^{57,58}$ Likewise, the histomorphologically similar high-grade astrocytoma CT-2A and GL261 tumors may be of different genetic subtypes that differ significantly in their responses to treatment. Both CT-2A and GL261 models were derived from malignant astrocytoma induced by intracranial implantation of methylcholanthrene (20- and 3-methylcholanthrene, respectively) in $\mathrm{C} 57 \mathrm{BL} / 6$ mice. The characterization of the underlying oncogenic mechanisms of CT-2A and GL261 tumors is limited. For example, both tumor types have $p 53$ mutations and are phosphatase and tensin (PTEN) homolog deficient, ${ }^{59,60}$ features that are seen in subsets of human GBM. In an attempt to further characterize the genetic landscape of these glioma cell lines, we evaluated whether CXCR4 mutations may be present, but found no evidence of mutations in the CXCR4 gene and its $5^{\prime}$ regulatory region in both glioma cell lines. In addition, the differences in the CXCR4 expression level and CXCR4-mediated migratory responses that we observed in CT-2A and GL261 tumors support the notion that the CXCR4 signal transduction pathways and therapeutic outcomes to CXCR4 inhibition may be distinct in these two cell lines despite being histomorphologically similar glioma tumors, as previously reported for primary patient-derived GBM cells. ${ }^{61}$ That CT-2A and GL261 gliomas did not always show similar responses to POL5551 and B20-4.1.1 may be best accounted for by being of different genetic subtypes that differ in their responses to treatment. 
Infiltrating most glioma tumors, macrophages/microglia comprise up to $30 \%$ of the tumor mass and have been associated with poor clinical prognosis in patients with high-grade glioma. ${ }^{8-10}$ Microglia, which commonly express Iba1 together with CD11b, are the main effector cells of the innate immune system in the central nervous system and perform a number of critical functions. Microglia promote glioma invasiveness not just by degrading the extracellular matrix through proteinase activity but also by stimulating cell mobility through the release of factors that activate the promigratory proline-rich tyrosine kinase 2 signaling pathway in glioma cells. ${ }^{62}$ Upon administration of antiVEGF therapy with aflibercept, a dramatic accumulation of Iba1-positive microglia/macrophages was noted at the tumor/normal brain interface in regions with heightened tumoral invasion, suggesting the presence of a myeloid population implicated in the escape of malignant glioma from anti-VEGF therapy. ${ }^{39}$ In addition to corroborating this finding using B20-4.1.1 antibody, we report that combined treatment with POL5551 significantly reduced the number of Iba1-positive cells in CT-2A glioma by half compared to control. This finding raises the possibility that CXCR4 PEM antagonists may interfere with the microglial mechanism of escape of malignant glioma from anti-VEGF therapy and have application in glioma immunotherapy analogous to that reported for AMD3100 in multikinase inhibitor (sorafenib)-treated hepatocellular carcinoma. ${ }^{63}$

GBMs contain a subpopulation of cells referred to herein as GSCs that possess self-renewal and tumor-initiating capacity and express neural stem cell markers, such as CD133 and nestin. ${ }^{25-27}$ CXCR4 was found to be highly expressed in a subpopulation of GSCs expandable by hypoxia, and treatment with AMD3100 inhibited the highly invasive growth of GSC engraftment and cell migration. ${ }^{26}$ Targeting of a similar population of GSCs by POL5551 may account for the significant reduction of nestin-positive cells observed in the CT-2A glioma model.

POL5551, combined with existing therapies, has previously been found to improve survival in immunodeficient mouse models. ${ }^{51,54}$ In U87 glioma-bearing mice, combined treatment with POL5551 (up to $80 \mathrm{mg} / \mathrm{kg}$ by osmotic pump) prolonged mouse survival compared to treatment with the anti-VEGF antibody mcr84 alone (35 versus 18 days). ${ }^{51}$ In an MDA-MB-231 breast cancer model, resection of the primary tumor followed by combined treatment with POL5551 also increased the survival compared with singleagent eribulin, a chemotherapeutic microtubule inhibitor (58 versus 51 days). ${ }^{54}$ CXCR4 antagonists are now being evaluated in clinical trials of cancer therapy. In patients with recurrent high-grade glioma, a clinical trial (NCT01339039) with combined treatment of AMD3100 and BEV is ongoing and recruiting patients. In patients with metastatic breast cancer, a clinical trial (NCT01837095) with combined treatment of the PEM CXCR4 antagonist POL6326 (a close analog of POL5551 that differs by a single amino acid) and eribulin was recently initiated. ${ }^{54}$
In conclusion, our study demonstrates that disruption of several CXCR4-regulated mechanisms with POL5551 can reduce intracranial glioma invasion through inhibition of hypoxia-induced glioma cell migration, as well as reduce the populations of tumor-initiating GSCs and tumorassociated MGCs known to promote glioma proliferation and invasion. Our results suggest that CXCR4-regulated mechanisms contribute to antiangiogenic therapy resistance. Adjunctive therapy with PEM CXCR4 antagonists may also help overcome antiangiogenic therapy resistance in patients with GBM and possibly in patients with other CXCR4expressing cancers.

\section{Acknowledgments}

We thank Dr. Thomas Seyfried (Boston College) for providing the CT-2A cell line, the National Cancer Institute (Frederick, MD) for providing the GL261 cell line, Caroline Kolopp (Polyphor Ltd) for determining the plasma and tissue concentrations of POL5551, Dr. Achim Wach for running simulations of the pharmacokinetic profiles, Dr. Mine Esencay and Sean Mahase (NYU Langone Medical Center) for performing initial cell migration experiments, Dr. Thales Papagiannakopolous for analyzing CXCR4 sequencing data, Dr. Jorge Ghiso for helping with glioma cell radioreceptor assays, Dr. Stefan Feske and Linda McCormack for helping with glioma cell calcium flux assays, Elad Mashiach for assisting with the diagrams and images, and Scott Kamen for assisting with editing.

\section{Supplemental Data}

Supplemental material for this article can be found at http://dx.doi.org/10.1016/j.ajpath.2017.04.020.

\section{References}

1. Lu KV, Bergers G: Mechanisms of evasive resistance to anti-VEGF therapy in glioblastoma. CNS Oncol 2013, 2:49-65

2. van Beijnum JR, Nowak-Sliwinska P, Huijbers EJ, Thijssen VL, Griffioen AW: The great escape: the hallmarks of resistance to antiangiogenic therapy. Pharmacol Rev 2015, 67:441-461

3. Plate KH, Scholz A, Dumont DJ: Tumor angiogenesis and antiangiogenic therapy in malignant gliomas revisited. Acta Neuropathol 2012, 124:763-775

4. Gagner JP, Golfinos JG, Graber JJ, Zagzag D: Molecular basis of glioma neovascularization and its therapeutic applications. Edited by Mehta M, Chang S, Newton H, Guha A, Vogelbaum M. In Principles and Practice of Neuro-Oncology: A Multidisciplinary Approach. New York: Demos Medical Publishing, 2011. pp. 122-144. i5-i7

5. Hardee ME, Zagzag D: Mechanisms of glioma-associated neovascularization. Am J Pathol 2012, 181:1126-1141

6. Fack F, Espedal H, Keunen O, Golebiewska A, Obad N, Harter PN Mittelbronn M, Bahr O, Weyerbrock A, Stuhr L, Miletic H, Sakariassen PO, Stieber D, Rygh CB, Lund-Johansen M, Zheng L, Gottlieb E, Niclou SP, Bjerkvig R: Bevacizumab treatment induces metabolic adaptation toward anaerobic metabolism in glioblastomas. Acta Neuropathol 2015, 129:115-131 
7. Pham K, Luo D, Siemann DW, Law BK, Reynolds BA, Hothi P, Foltz G, Harrison JK: VEGFR inhibitors upregulate CXCR4 in VEGF receptor-expressing glioblastoma in a TGFbetaR signalingdependent manner. Cancer Lett 2015, 360:60-67

8. Piao Y, Liang J, Holmes L, Zurita AJ, Henry V, Heymach JV, de Groot JF: Glioblastoma resistance to anti-VEGF therapy is associated with myeloid cell infiltration, stem cell accumulation, and a mesenchymal phenotype. Neuro Oncol 2012, 14: $1379-1392$

9. Wurdinger T, Deumelandt $\mathrm{K}$, van der Vliet HJ, Wesseling $\mathrm{P}$, de Gruijl TD: Mechanisms of intimate and long-distance cross-talk between glioma and myeloid cells: how to break a vicious cycle. Biochim Biophys Acta 2014, 1846:560-575

10. Hambardzumyan D, Gutmann DH, Kettenmann H: The role of microglia and macrophages in glioma maintenance and progression. Nat Neurosci 2015, 19:20-27

11. Fine HA: New strategies in glioblastoma: exploiting the new biology. Clin Cancer Res 2015, 21:1984-1988

12. Jahangiri A, De Lay M, Miller LM, Carbonell WS, Hu YL, Lu K, Tom MW, Paquette J, Tokuyasu TA, Tsao S, Marshall R, Perry A, Bjorgan KM, Chaumeil MM, Ronen SM, Bergers G, Aghi MK: Gene expression profile identifies tyrosine kinase c-Met as a targetable mediator of antiangiogenic therapy resistance. Clin Cancer Res 2013, 19:1773-1783

13. Gilbert MR: Renewing interest in targeting angiogenesis in glioblastoma. Lancet Oncol 2014, 15:907-908

14. Taal W, Oosterkamp HM, Walenkamp AM, Dubbink HJ, Beerepoot LV, Hanse MC, Buter J, Honkoop AH, Boerman D, de Vos FY, Dinjens WN, Enting RH, Taphoorn MJ, van den Berkmortel FW, Jansen RL, Brandsma D, Bromberg JE, van Heuvel I, Vernhout RM, van der Holt B, van den Bent MJ: Singleagent bevacizumab or lomustine versus a combination of bevacizumab plus lomustine in patients with recurrent glioblastoma (BELOB trial): a randomised controlled phase 2 trial. Lancet Oncol 2014, 15:943-953

15. Sandmann T, Bourgon R, Garcia J, Li C, Cloughesy T, Chinot OL, Wick W, Nishikawa R, Mason W, Henriksson R, Saran F, Lai A, Moore N, Kharbanda S, Peale F, Hegde P, Abrey LE, Phillips HS, Bais C: Patients with proneural glioblastoma may derive overall survival benefit from the addition of Bevacizumab to first-line radiotherapy and Temozolomide: retrospective analysis of the AVAglio Trial. J Clin Oncol 2015, 33:2735-2744

16. Batchelor TT, Gerstner ER, Emblem KE, Duda DG, KalpathyCramer J, Snuderl M, Ancukiewicz M, Polaskova P, Pinho MC, Jennings D, Plotkin SR, Chi AS, Eichler AF, Dietrich J, Hochberg FH, Lu-Emerson C, Iafrate AJ, Ivy SP, Rosen BR, Loeffler JS, Wen PY, Sorensen AG, Jain RK: Improved tumor oxygenation and survival in glioblastoma patients who show increased blood perfusion after cediranib and chemoradiation. Proc Natl Acad Sci U S A 2013, 110:19059-19064

17. Chatterjee S, Behnam Azad B, Nimmagadda S: The intricate role of CXCR4 in cancer. Adv Cancer Res 2014, 124:31-82

18. Ehtesham M, Min E, Issar NM, Kasl RA, Khan IS, Thompson RC: The role of the CXCR4 cell surface chemokine receptor in glioma biology. J Neurooncol 2013, 113:153-162

19. Gagliardi F, Narayanan A, Reni M, Franzin A, Mazza E, Boari N, Bailo M, Zordan P, Mortini P: The role of CXCR4 in highly malignant human gliomas biology: current knowledge and future directions. Glia 2014, 62:1015-1023

20. Tabouret E, Tchoghandjian A, Denicolai E, Delfino C, Metellus P, Graillon T, Boucard C, Nanni I, Padovani L, Ouafik L, FigarellaBranger D, Chinot O: Recurrence of glioblastoma after radiochemotherapy is associated with an angiogenic switch to the CXCL12-CXCR4 pathway. Oncotarget 2015, 6:11664-11675

21. Tang W, Wang X, Chen Y, Zhang J, Chen Y, Lin Z: CXCL12 and CXCR4 as predictive biomarkers of glioma recurrence pattern after total resection. Pathol Biol (Paris) 2015, 63:190-198
22. Zagzag D, Lukyanov Y, Lan L, Ali MA, Esencay M, Mendez O, Yee H, Voura EB, Newcomb EW: Hypoxia-inducible factor 1 and VEGF upregulate CXCR4 in glioblastoma: implications for angiogenesis and glioma cell invasion. Lab Invest 2006, 86:1221-1232

23. Zagzag D, Esencay M, Mendez O, Yee H, Smirnova I, Huang Y, Chiriboga L, Lukyanov E, Liu M, Newcomb EW: Hypoxia- and vascular endothelial growth factor-induced stromal cell-derived factor-1alpha/CXCR4 expression in glioblastomas: one plausible explanation of Scherer's structures. Am J Pathol 2008, 173:545-560

24. Xu CS, Wang ZF, Dai LM, Chu SH, Gong LL, Yang MH, Li ZQ: Induction of proline-rich tyrosine kinase 2 activation-mediated C6 glioma cell invasion after anti-vascular endothelial growth factor therapy. J Transl Med 2014, 12:148

25. Zhao D, Najbauer J, Garcia E, Metz MZ, Gutova M, Glackin CA, Kim SU, Aboody KS: Neural stem cell tropism to glioma: critical role of tumor hypoxia. Mol Cancer Res 2008, 6:1819-1829

26. Schulte A, Gunther HS, Phillips HS, Kemming D, Martens T, Kharbanda S, Soriano RH, Modrusan Z, Zapf S, Westphal M, Lamszus K: A distinct subset of glioma cell lines with stem cell-like properties reflects the transcriptional phenotype of glioblastomas and overexpresses CXCR4 as therapeutic target. Glia 2011, 59:590-602

27. Goffart N, Kroonen J, Di Valentin E, Dedobbeleer M, Denne A, Martinive P, Rogister B: Adult mouse subventricular zones stimulate glioblastoma stem cells specific invasion through CXCL12/CXCR4 signaling. Neuro Oncol 2015, 17:81-94

28. Duda DG, Kozin SV, Kirkpatrick ND, Xu L, Fukumura D, Jain RK: CXCL12 (SDF1alpha)-CXCR4/CXCR7 pathway inhibition: an emerging sensitizer for anticancer therapies? Clin Cancer Res 2011, 17:2074-2080

29. Liu SC, Alomran R, Chernikova SB, Lartey F, Stafford J, Jang T, Merchant M, Zboralski D, Zollner S, Kruschinski A, Klussmann S, Recht L, Brown JM: Blockade of SDF-1 after irradiation inhibits tumor recurrences of autochthonous brain tumors in rats. Neuro Oncol 2014, 16:21-28

30. Gatti M, Pattarozzi A, Bajetto A, Wurth R, Daga A, Fiaschi P, Zona G, Florio T, Barbieri F: Inhibition of CXCL12/CXCR4 autocrine/paracrine loop reduces viability of human glioblastoma stem-like cells affecting self-renewal activity. Toxicology 2013, 314:209-220

31. Karpova D, Dauber K, Spohn G, Chudziak D, Wiercinska E, Schulz M, Pettit AR, Levesque JP, Romagnoli B, Patel K, Chevalier E, Dembowsky K, Bonig H: The novel CXCR4 antagonist POL5551 mobilizes hematopoietic stem and progenitor cells with greater efficiency than Plerixafor. Leukemia 2013, 27:2322-2331

32. Obrecht D, Chevalier E, Moehle K, Robinson JA: $\beta$-Hairpin protein epitope mimetic technology in drug discovery. Drug Discov Today Technol 2012, 9:e63-e69

33. Seyfried NT, Huysentruyt LC, Atwood JA 3rd, Xia Q, Seyfried TN, Orlando R: Up-regulation of NG2 proteoglycan and interferoninduced transmembrane proteins 1 and 3 in mouse astrocytoma: a membrane proteomics approach. Cancer Lett 2008, 263:243-252

34. Zagzag D, Miller DC, Chiriboga L, Yee H, Newcomb EW: Green fluorescent protein immunohistochemistry as a novel experimental tool for the detection of glioma cell invasion in vivo. Brain Pathol (Zurich, Switzerland) 2003, 13:34-37

35. Bagri A, Berry L, Gunter B, Singh M, Kasman I, Damico LA, Xiang H, Schmidt M, Fuh G, Hollister B, Rosen O, Plowman GD: Effects of anti-VEGF treatment duration on tumor growth, tumor regrowth, and treatment efficacy. Clin Cancer Res 2010, 16: $3887-3900$

36. Glass R, Synowitz M: CNS macrophages and peripheral myeloid cells in brain tumours. Acta Neuropathol 2014, 128:347-362

37. Committee for the Update of the Guide for the Care and Use of Laboratory Animals; National Research Council: Guide for the Care and Use of Laboratory Animals. ed 8. Washington, DC, National Academies Press, 2011

38. Colman H, Giannini C, Huang L, Gonzalez J, Hess K, Bruner J, Fuller G, Langford L, Pelloski C, Aaron J, Burger P, Aldape K: 
Assessment and prognostic significance of mitotic index using the mitosis marker phospho-histone $\mathrm{H} 3$ in low and intermediate-grade infiltrating astrocytomas. Am J Surg Pathol 2006, 30:657-664

39. Gabrusiewicz K, Liu D, Cortes-Santiago N, Hossain MB, Conrad CA, Aldape KD, Fuller GN, Marini FC, Alonso MM, Idoate MA, Gilbert MR, Fueyo J, Gomez-Manzano C: Anti-vascular endothelial growth factor therapy-induced glioma invasion is associated with accumulation of Tie2-expressing monocytes. Oncotarget 2014, 5:2208-2220

40. Shen W, Hu XM, Liu YN, Han Y, Chen LP, Wang CC, Song C: CXCL12 in astrocytes contributes to bone cancer pain through CXCR4-mediated neuronal sensitization and glial activation in rat spinal cord. J Neuroinflammation 2014, 11:75

41. Binello E, Qadeer ZA, Kothari HP, Emdad L, Germano IM: Stemness of the CT-2A immunocompetent mouse brain tumor model: characterization in vitro. J Cancer 2012, 3:166-174

42. Jin $X$, Jin $X$, Jung JE, Beck S, Kim H: Cell surface Nestin is a biomarker for glioma stem cells. Biochem Biophys Res Commun 2013, 433:496-501

43. Sottoriva A, Verhoeff JJ, Borovski T, McWeeney SK, Naumov L, Medema JP, Sloot PM, Vermeulen L: Cancer stem cell tumor model reveals invasive morphology and increased phenotypical heterogeneity. Cancer Res 2010, 70:46-56

44. Zwier JM, Roux T, Cottet M, Durroux T, Douzon S, Bdioui S, Gregor N, Bourrier E, Oueslati N, Nicolas L, Tinel N, Boisseau C, Yverneau P, Charrier-Savournin F, Fink M, Trinquet E: A fluorescent ligand-binding alternative using Tag-lite(R) technology. J Biomol Screen 2010, 15:1248-1259

45. Engl T, Relja B, Marian D, Blumenberg C, Muller I, Beecken WD, Jones J, Ringel EM, Bereiter-Hahn J, Jonas D, Blaheta RA: CXCR4 chemokine receptor mediates prostate tumor cell adhesion through alpha5 and beta3 integrins. Neoplasia (New York, NY) 2006, 8: 290-301

46. Newcomb EW, Lukyanov Y, Schnee T, Esencay M, Fischer I, Hong D, Shao Y, Zagzag D: The geldanamycin analogue 17allylamino-17-demethoxygeldanamycin inhibits the growth of GL261 glioma cells in vitro and in vivo. Anticancer Drugs 2007, 18:875-882

47. Moserle L, Jimenez-Valerio G, Casanovas O: Antiangiogenic therapies: going beyond their limits. Cancer Discov 2014, 4:31-41

48. Laufer S, Mazuz A, Nachmansson N, Fellig Y, Corn BW, Bokstein F, Bashat DB, Abramovitch R: Monitoring brain tumor vascular heamodynamic following anti-angiogenic therapy with advanced magnetic resonance imaging in mice. PLoS One 2014, 9: e115093

49. Bajetto A, Barbieri F, Dorcaratto A, Barbero S, Daga A, Porcile C, Ravetti JL, Zona G, Spaziante R, Corte G, Schettini G, Florio T: Expression of CXC chemokine receptors 1-5 and their ligands in human glioma tissues: role of CXCR4 and SDF1 in glioma cell proliferation and migration. Neurochem Int 2006, 49:423-432

50. Najbauer J, Huszthy PC, Barish ME, Garcia E, Metz MZ, Myers SM, Gutova M, Frank RT, Miletic H, Kendall SE, Glackin CA, Bjerkvig R, Aboody KS: Cellular host responses to gliomas. PLoS One 2012, 7:e35150

51. Barone A, Sengupta R, Warrington NM, Smith E, Wen PY, Brekken RA, Romagnoli B, Douglas G, Chevalier E, Bauer MP, Dembowsky K, Piwnica-Worms D, Rubin JB: Combined VEGF and CXCR4 antagonism targets the GBM stem cell population and synergistically improves survival in an intracranial mouse model of glioblastoma. Oncotarget 2014, 5:9811-9822

52. Matsusaka S, Cao S, Hanna DL, Sunakawa $\mathrm{Y}$, Ueno $\mathrm{M}$, Mizunuma N, Zhang W, Yang D, Ning Y, Stintzing S, Sebio A, Stremitzer S, Yamauchi S, Parekh A, Okazaki S, Berger MD, ElKhoueiry R, Mendez A, Ichikawa W, Loupakis F, Lenz HJ: CXCR4 polymorphism predicts progression-free survival in metastatic colorectal cancer patients treated with first-line bevacizumab-based chemotherapy. Pharmacogenomics J 2016, [Epub ahead of print] doi: $10.1038 /$ tpj.2016.59

53. Kim HK, De La Luz Sierra M, Williams CK, Gulino AV, Tosato G: GCSF down-regulation of CXCR4 expression identified as a mechanism for mobilization of myeloid cells. Blood 2006, 108:812-820

54. Xiang J, Hurchla MA, Fontana F, Su X, Amend SR, Esser AK, Douglas GJ, Mudalagiriyappa C, Luker KE, Pluard T, Ademuyiwa FO, Romagnoli B, Tuffin G, Chevalier E, Luker GD, Bauer M, Zimmermann J, Aft RL, Dembowsky K, Weilbaecher KN CXCR4 protein epitope mimetic antagonist POL5551 disrupts metastasis and enhances chemotherapy effect in triple-negative breast cancer. Mol Cancer Ther 2015, 14:2473-2485

55. Wei J, Wu A, Kong LY, Wang Y, Fuller G, Fokt I, Melillo G, Priebe W, Heimberger AB: Hypoxia potentiates glioma-mediated immunosuppression. PLoS One 2011, 6:e16195

56. Chae M, Peterson TE, Balgeman A, Chen S, Zhang L, Renner DN, Johnson AJ, Parney IF: Increasing glioma-associated monocytes leads to increased intratumoral and systemic myeloid-derived suppressor cells in a murine model. Neuro Oncol 2015, 17:978-991

57. Louis DN, Ohgaki H, Wiestler OD, Cavenee WK, Ellison DW, Figarella-Branger D, Perry A, Reifenberger G, Von Deimling A: WHO Classification of Tumours of the Central Nervous System. revised ed 4. Lyon, France, International Agency for Research on Cancer, 2016

58. Thomas CJ, Gagner JP, Baitalmal R, Zagzag D: Translating molecular biomarkers of gliomas to clinical practice. Edited by Brem S, Abdullah KG. In Glioblastoma. ed 1. Amsterdam: Elsevier, 2016. pp. $33-53$

59. Martinez-Murillo R, Martinez A: Standardization of an orthotopic mouse brain tumor model following transplantation of CT-2A astrocytoma cells. Histol Histopathol 2007, 22:1309-1326

60. Szatmari T, Lumniczky K, Desaknai S, Trajcevski S, Hidvegi EJ, Hamada H, Safrany G: Detailed characterization of the mouse glioma 261 tumor model for experimental glioblastoma therapy. Cancer Sci 2006, 97:546-553

61. Liu C, Pham K, Luo D, Reynolds BA, Hothi P, Foltz G, Harrison JK: Expression and functional heterogeneity of chemokine receptors CXCR4 and CXCR7 in primary patient-derived glioblastoma cells. PLoS One 2013, 8:e59750

62. Rolon-Reyes K, Kucheryavykh YV, Cubano LA, Inyushin M, Skatchkov SN, Eaton MJ, Harrison JK, Kucheryavykh LY: Microglia activate migration of glioma cells through a Pyk2 intracellular pathway. PLoS One 2015, 10:e131059

63. Chen Y, Ramjiawan RR, Reiberger T, Ng MR, Hato T, Huang Y, Ochiai H, Kitahara S, Unan EC, Reddy TP, Fan C, Huang P, Bardeesy N, Zhu AX, Jain RK, Duda DG: CXCR4 inhibition in tumor microenvironment facilitates anti-programmed death receptor-1 immunotherapy in sorafenib-treated hepatocellular carcinoma in mice. Hepatology 2015, 61:1591-1602 